Prepared in cooperation with the U.S. Fish and Wildlife Service

\title{
User's Manual to Update the National Wildlife Refuge System Water Quality Information System (WOIS)
}

Chapter 8 of

Section C, Geographic Information Systems tools and applications Book 11, Collection and Delineation of Spatial Data

Techniques and Methods 11-C8 



\section{User's Manual to Update the National Wildlife Refuge System Water Quality Information System (WOIS)}

By Kimberly A. Chojnacki, Chad J. Vishy, Jo Ellen Hinck, Susan E. Finger, Michael J. Higgins, and Kevin Kilbride

Chapter 8 of

Section C, Geographic Information Systems tools and applications

Book 11, Collection and Delineation of Spatial Data

Prepared in cooperation with the U.S. Fish and Wildlife Service

Techniques and Methods 11-C8 


\section{U.S. Department of the Interior \\ KEN SALAZAR, Secretary \\ U.S. Geological Survey \\ Marcia K. McNutt, Director}

U.S. Geological Survey, Reston, Virginia: 2013

For more information on the USGS - the Federal source for science about the Earth, its natural and living resources, natural hazards, and the environment, visit http://www.usgs.gov or call 1-888-ASK-USGS.

For an overview of USGS information products, including maps, imagery, and publications, visit http://www.usgs.gov/pubprod

To order this and other USGS information products, visit http://store.usgs.gov

Any use of trade, firm, or product names is for descriptive purposes only and does not imply endorsement by the U.S. Government.

Although this information product, for the most part, is in the public domain, it also may contain copyrighted materials as noted in the text. Permission to reproduce copyrighted items must be secured from the copyright owner.

Suggested citation:

Chojnacki, K.A., Vishy, C.J., Hinck, J.E., Finger, S.E., Higgins, M.J., and Kilbride, Kevin, 2013, User's manual to update the National Wildlife Refuge System Water Quality Information System (WQIS): U.S. Geological Survey Techniques and Methods, book 11, chap. C8, 24 p. 


\section{Contents}

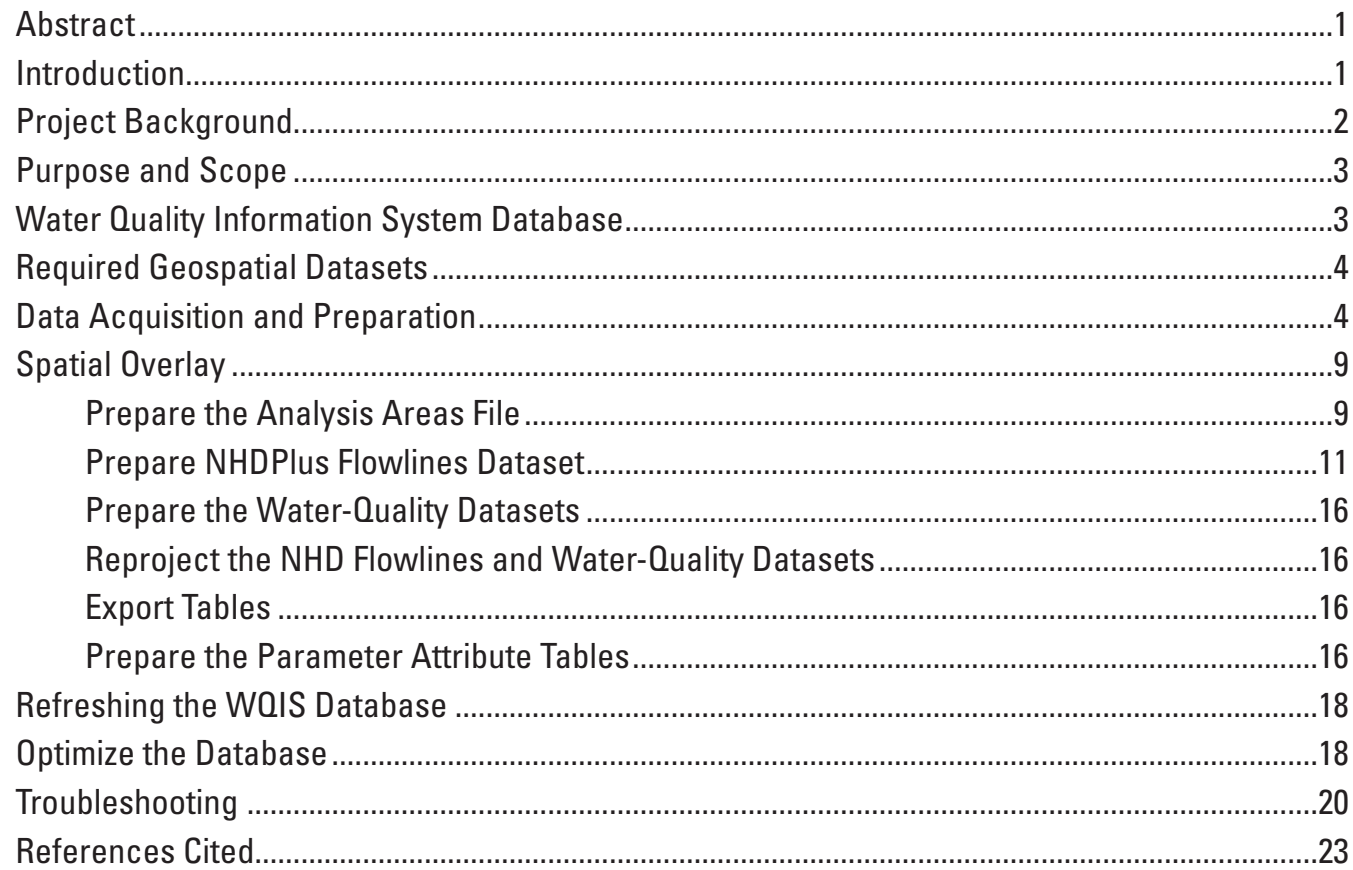

\section{Figures}

1. Screen capture of the U.S. Fish and Wildlife Service Geospatial Services

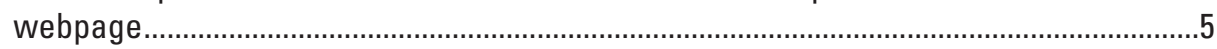

2. Screen capture of the NHDPlus Web site showing the NHDPlus Data link.....................6

3. Screen capture of the NHDPlus Version 1 archive Web site .............................................

4. Screen capture of the NHDPlus regions .........................................................................

5. Screen capture of the NHDPlus version 1 datasets .............................................................

6. Screen capture of the U.S. Environmental Protection Agency Reach Address Database Download Web site ........................................................................................8

7. Screen capture of the National Geospatial Datasets webpage..........................................8

8. Screen capture of the Clean Water Act Section 303(d) Listed Impaired Waters Download webpage .........................................................................................................

9. Screen capture showing the creation of a new file geodatabase in ArcCatalog ............9

10. Screen capture of adding the FwsApproved and FwsInterest data layers to ArcMap.

11. Screen capture of the Query Builder expression used to display only National Wildlife Refuges...

12. Screen capture of the Select by Attributes tool used to select the approved boundaries for all Refuges EXCEPT the four large Refuges in the FwsApproved data layer

13. Screen capture of the Select by Attributes tool used to select the boundaries of the four Refuges in the FwsInterest data layer..... 
14. Screen capture of the Merge tool used to combine boundaries from both the FwsApproved and FwsInterest data layers.

15. Screen capture of the NDHflowline data layer within a NHDPlus geodatabase ............12

16. Screen capture of the Clip tool used to clip the NHDflowlines from each National Hydrography Dataset region to refuge boundaries using the Analysis Areas data layer created previously

17. Screen capture of the Merge tool to combine the clipped NHDflowlines from each National Hydrography Dataset region into one seamless national NHDflowlines layer.....

18. Screen capture of the Spatial Join function to add refuge attributes to the NHDflowline data layer.

19. Screen capture of the Select by Attributes tool used to select stream segments with null values in the GNIS_Name column.

20. Screen capture of the Query Builder expression used to eliminate artificial path, coastline, and pipeline features from the NHDflowline dataset representation in ArcMap.

21. Screen capture of the Project tool used to convert the prepared datasets to a projected coordinate system.

22. Screen capture of Exporting the attribute table for the prepared files; NHDflowlines, Clean Water Act Section 303(d) listed impaired waters, and total maximum daily load data layer.

23. Screen capture of saving the data table exported from ArcGIS as a .dbf file

24. Screen capture of the parameter attribute table for Clean Water Act Section 303(d) impaired waters within the U.S. Environmental Protection Agency RAD_303(d) geodatabase..

25. Screen capture showing the side-by-side comparison of fields contained in the old Impaired and new Impaired1 versions of the table ................................................19

26. Screen capture showing the Dates table within the WOIS database .............................19

27. Screen capture of the Performance Analyzer tools in Microsoft Access........................20

28. Screen capture of the Performance Analyzer results ......................................................21

29. Screen capture of the Access Options to configure Microsoft Access to

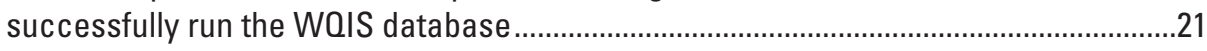

30. Screen capture of the Access Options box in Microsoft Access ....................................22

31. Screen capture of the Macro Settings within the Microsoft Access Trust Center.........22

32. Screen capture of the Enable Data Execution Prevention setting in the Microsoft Access Trust Center

\section{Tables}

1. Water-quality standard attainment categories based on U.S. Environmental Protection Agency guidance. .2

2. Data tables contained in the Water Quality Information System database

3. Geospatial datasets and their sources used to summarize water-quality issues on National Wildlife Refuges 


\title{
User's Manual to Update the National Wildlife Refuge System Water Quality Information System (WOIS)
}

\author{
By Kimberly A. Chojnacki, Chad J. Vishy, Jo Ellen Hinck, Susan E. Finger, Michael J. Higgins, and Kevin \\ Kilbride
}

\section{Abstract}

National Wildlife Refuges may have impaired water quality resulting from historic and current land uses, upstream sources, and aerial pollutant deposition. National Wildlife Refuge staff have limited time available to identify and evaluate potential water quality issues. As a result, water qualityrelated issues may not be resolved until a problem has already arisen. The National Wildlife Refuge System Water Quality Information System (WQIS) is a relational database developed for use by U.S. Fish and Wildlife Service staff to identify existing water quality issues on refuges in the United States. The WQIS database relies on a geospatial overlay analysis of data layers for ownership, streams and water quality. The WQIS provides summary statistics of 303(d) impaired waters and total maximum daily loads for the National Wildlife Refuge System at the national, regional, and refuge level. The WQIS allows U.S. Fish and Wildlife Service staff to be proactive in addressing water quality issues by identifying and understanding the current extent and nature of 303(d) impaired waters and subsequent total maximum daily loads. Water quality data are updated bi-annually, making it necessary to refresh the WQIS to maintain up-to-date information. This manual outlines the steps necessary to update the data and reports in the WQIS.

\section{Introduction}

The National Wildlife Refuge System (NWRS) is a network of public lands and waters managed by the U.S. Fish and Wildlife Service (FWS). The mission of the NWRS is to conserve, protect and enhance biological resources and habitat for the benefit of present and future generations of Americans (U.S. Fish and Wildlife Service, 2011). Many National Wildlife Refuges (refuges) have water quality impairments resulting from previous and current land uses, transport of pollutants from off-refuge, upstream sources, and aerial pollutant deposition. These new and existing impairments often elude refuge staff until a problem arises, as much of their time is spent on daily resource management duties. Legal mandates on National Wildlife Refuge System lands include the amended National Wildlife Refuge System Administration Act for Refuge purpose and water quality protection (16 U.S.C. 668dd-668ee; Code of Federal Regulations, 2012a); the Migratory Bird Treaty Act (16 U.S.C. 703-711), the Endangered Species Act (16 U.S.C. 11 1531-1544, December 28, 1973, as amended 1976-1982, 1984 and 1988), and the Marine Mammal Protection Act (16 U.S.C. 1361-1471h) for addressing FWS biological resources (Code of Federal Regulations, 2012a); and FWS Manual Chapter 601 FW 3-Biological Integrity, Diversity, and Environmental Health for maintaining and restoring biological integrity, diversity, and environmental health (U.S. Fish and Wildlife Service, 2012a).

The Clean Water Act was established in 1972 to restore and maintain the chemical, physical, and biological integrity of surface waters in the United States (Code of Federal Regulations, 2012b). Water-quality standards, the conceptual basis for the surface-water pollution control program of the Clean Water Act, define the goals for a water body by designating its uses (for example, drinking water supply, primary or secondary contact recreation, aquatic life use support), setting criteria to protect those uses, and establishing antidegradation provisions. Under Clean Water Act Section 305(b), states are required to prepare biennial water-quality assessment reports that identify where and why navigable water bodies are not meeting state water-quality standards. The term "navigable waters" includes; (1) all navigable waters of the United States, as defined in judicial decisions before the passage of the 1972 Amendments of the Federal Water Pollution Control Act, also known as the Clean Water Act, and tributaries of such waters as, (2) interstate waters, (3) intrastate lakes, rivers, and streams that are used by interstate travelers for recreational or other purposes, and (4) intrastate lakes, rivers, and streams from which fish or shellfish are taken and sold in interstate commerce (Code of Federal Regulations, 2008).

Water bodies that do not meet water-quality standards are considered "water quality-limited" and placed on the impaired waters list in the Clean Water Act Section 303(d), hereinafter known as 303(d). Impaired water bodies are placed into one of five categories representing different levels of water-quality standard attainment based on U.S. Environmental Protection Agency (EPA) guidance (table 1; U.S. Environmental 
Table 1. Water-quality standard attainment categories based on U.S. Environmental Protection Agency guidance.

[From Guidance for 2004 assessment, listing, and reporting requirements pursuant to Sections 303(d) and 305(b) of the Clean Water Act (U.S. Environmental Protection Agency, 2003)]

\begin{tabular}{cl}
\hline Category & \multicolumn{1}{c}{ Description } \\
\hline 1 & All designated uses are met. \\
2 & Some designated uses are met but insufficient data for remaining designated uses. \\
3 & Insufficient data to determine if any designated uses are met. \\
3B & Insufficient data but some data indicate nonattainment of applicable water-quality standards have been approved. \\
4A & All total maximum daily loads needed for attainment of applicable water-quality standards have been approved. \\
4B & Other pollution control requirements are expected to address all pollutants and will attain water-quality standards. \\
4C & Impairment is not caused by a pollutant. \\
5 & Water is impaired or threatened and a total maximum daily load is needed. \\
\hline
\end{tabular}

Protection Agency, 2003). Once a water body is listed as 303(d) impaired, the Clean Water Act requires the state to develop a total maximum daily load (TMDL) for the impaired water to protect beneficial uses by minimizing further degradation. After the TMDL is approved by the EPA, an implementation plan is prepared and initiated by the state. A TMDL is an estimate of the maximum amount of a pollutant that a water body can receive and still meet the water-quality standards. It is calculated as the sum of (1) waste load allocation, which is the amount of pollutant from all existing point sources (such as, sewage treatment plant; industrial facility), (2) load allocation, which is the amount of pollutant from existing nonpoint sources and natural background (for example, runoff or atmospheric deposition), and (3) a margin of safety that reflects uncertainty associated with the TMDL estimate. A TMDL commonly targets anthropogenic sources such as agriculture, silviculture, industry, and urban centers (such as, stormwater runoff). In addition, discharges from natural and managed wetlands or other aquatic habitats also are affected by load-limit regulations. Because reporting on the status of implementation is currently (2012) not required under the Clean Water Act or by EPA, it is often difficult to assess progress toward meeting a TMDL (Hinck and others, 2011).

The regulatory requirements associated with a TMDL represent one of the ultimate challenges for adaptive management on refuges. States prepare and apply TMDL implementation plans that allocate contaminant load limits among all discharges within a watershed (including wetlands) to maintain or improve water quality. Although wetland and water management on refuges may be affected by or contribute to the establishment and implementation of a TMDL, many refuges are not prepared to adapt to an existing or proposed TMDL. Specifically, a TMDL may force alterations of refuge water-management programs (for example, limiting wetland drawdowns) that can affect the quantity and quality of refuge aquatic habitats. A TMDL also may affect FWS-coordinated efforts for resource management with conservation partners in larger landscapes beyond refuge boundaries.

\section{Project Background}

This project builds on a cooperative project initiated in 2008 (Hinck and others, 2011) involving FWS, U.S. Geological Survey (USGS), and EPA. In the initial project, USGS developed a geospatial approach to identify and prioritize water-quality issues affecting resources of concern within refuge boundaries (Hinck and others, 2011). The nature of 303(d) impaired waters and TMDLs within individual refuges were assessed with a geospatially-based application for two pilot states in FWS Region 1 (Oregon and Washington). Products from this project included; summary statistics of 303(d) impaired waters and TMDLs for the region, as well as a Geographic Information System (GIS) based module that included all pertinent geospatial data layers. Individual refuge summaries allow for FWS staff to be proactive in addressing water-quality issues by identifying and understanding the current extent and nature of 303(d) impaired waters and TMDLs. With this information, refuge staffs can evaluate the effect of current management actions on 303(d) impaired waters and subsequent TMDLs, as well as identify best management practices to protect and enhance water quality.

The concept of the initial project in Oregon and Washington was then applied to create a national database (Water Quality Information System; WQIS), which included summary statistics of 303(d) impaired waters and TMDLs for the NWRS at the national, regional, and refuge level using linear stream-segment geospatial data. Such information is useful to develop Water Resource Inventory and Assessment reports, Comprehensive Conservation Plans, and Contaminant Assessment Process reports. Information on using the WQIS, including frequently asked questions and troubleshooting, is contained within the database itself. The WQIS was developed for ultimate inclusion as a module in the Environmental Conservation Online System of FWS. 


\section{Purpose and Scope}

The WQIS is a relational database developed for use by FWS staff to identify existing water-quality impaired streams on refuges in the United States, excluding Alaska. The WQIS provides summary statistics of 303(d) impaired waters and TMDLs for the NWRS at the national, regional, and refuge level. The WQIS also generates a National Score Card report that provides an abbreviated summary of water-quality issues. This version of the WQIS database includes data for refuges only, not Wetland Management Districts or Waterfowl Production Areas.

The WQIS database relies on a geospatial overlay analysis of data layers for land ownership, streams, and water quality. The EPA water-quality data required for this project are updated bi-annually, making it necessary to refresh the analysis to maintain up-to-date reports. This User's Manual documents and describes the methods used to identify 303(d) listed impaired streams and streams with established TMDLs within approved refuge boundaries. It is important to note that impairments for nonlinear water features (such as, lakes and wetlands) are NOT included in this version of the WQIS database. Additionally, this document describes the development of the WQIS database and the method to update the database and the reports contained therein.

\section{Water Quality Information System Database}

The WQIS database was developed by USGS using Microsoft Access (Microsoft Corporation, Seattle, Wash.) to provide a flexible and portable database platform. Each table in the database is designed to store a specific and defined set of data, in which each record has a mutually exclusive identifier. Data stored in one table can be linked (related) to data in another table using the mutually exclusive identifiers. These linkages are established and maintained within the database, making it possible to combine data from multiple tables into one report. These linkages are maintained even when the data tables are updated, as long as the table and field names involved in the relationship remain constant in the database.

The Microsoft Access platform also provided the opportunity to develop a user interface, allowing users to quickly view a series of custom reports summarizing information from multiple tables. Reports providing summary statistics of 303(d) impaired waters and TMDLs for refuges at the national, regional and refuge level have been made easily accessible through the custom WQIS user interface.

The WQIS consists of nine tables (table 2). Table names are italicized to improve readability. The $N H D$, Impaired and $T M D L$ tables are derived from a spatial overlay analysis in a GIS. The Impatt and TMDLatt are attribute tables providing detailed information about the parameters for each 303(d) impairment and established TMDL. The Dates table contains publication dates for the FWS cadastral dataset and

Table 2. Data tables contained in the Water Quality Information System database.

[TMDL, total maximum daily load]

\begin{tabular}{|c|c|}
\hline Table name & Description \\
\hline Dates & $\begin{array}{l}\text { Table containing the publication dates for the U.S. Fish and Wildlife Service cadastral and U.S. Environmental Protec- } \\
\text { tion Agency water-quality data. }\end{array}$ \\
\hline Impaired & $\begin{array}{l}\text { Table containing data for Clean Water Act Section 303(d) listed impaired stream segments within refuge boundaries. } \\
\text { Extracted from spatial overlay analysis. }\end{array}$ \\
\hline TMDL & $\begin{array}{l}\text { Table containing data for TMDL on impaired stream segments within refuge boundaries. Extracted from spatial overlay } \\
\text { analysis. }\end{array}$ \\
\hline TMDLatt & $\begin{array}{l}\text { Additional descriptive attribute information for each established TMDL linked in a one-to-many relationship to the } \\
\text { TMDL table using the SourceFeatureID. }\end{array}$ \\
\hline States & $\begin{array}{l}\text { Table containing the name and state(s) of each refuge, used to link with the cycle date in each EPA water-quality tables } \\
\text { (Impaired and TMDL). }\end{array}$ \\
\hline
\end{tabular}


EPA water-quality datasets. This information is incorporated into the header of all the summary reports, providing the user information on the publication date of the data being reported. The States table includes a complete refuge name list and the state(s) in which each refuge is contained. These data are linked to the Impaired and TMDL tables to provide the reporting-cycle year information. The EPA reporting-cycle year is included in the summary reports so that the user understands how current the data are. The RankImp and RankTMDL tables provide the top five 303(d) impairment parameters and TMDL parameters, respectively, for each FWS region. These two tables are created dynamically by the WQIS database and are necessary for the generation of the National Score Card report.

\section{Required Geospatial Datasets}

Required geospatial datasets include FWS cadastral geodatabase, NHDPlus datasets, and water-quality datasets from EPA (table 3). The FWS cadastral geodatabase contains FWS Approved, FWS Interest, and Special Designation data layers. The FWS Approved dataset represents the external boundaries of lands and waters that are approved for acquisition by FWS. The FWS Interest dataset represents fee title lands and less-than fee lands (for example, easements) and may include inholding lands within acquisition boundaries. The Special Designation dataset represents other designations, such as Wilderness and Wild and Scenic Rivers on FWS managed lands.

NHDPlus data were obtained for all hydrologic regions within the contiguous United States and Hawaii. These data do not yet exist for Alaska. The NHDPlus is an integrated suite of geospatial datasets incorporating many features from the National Hydrography Dataset (NHD), the National Elevation Dataset (NED), the National Land Cover Dataset (NLCD) and the Watershed Boundary Dataset (WBD) (NHDPlus Team, 2010). The NHDPlus data provides a comprehensive stream centerline network based on the medium resolution NHD $(1: 100,000)$. Linkages have been developed by EPA between the NHDPlus and numerous EPA water-quality databases by assigning NHD stream reach addresses (NHDPlus Team, 2010). NHDPlus Version 1 was used for the initial development of the WQIS, as NHDPlus Version 2 had not yet been released. The data structure of the NHDPlus Version 2 has only minor modifications and could therefore be used in lieu of Version 1. Make note that the Version 2 data has not been released for Hawaii (2012).

Water-quality datasets are available from the EPA including 303(d) listed impaired waters and TMDLs data layers (table 3). The 303(d) impaired waters dataset includes waters identified as Attainment Category 5 (table 1). Geospatial data on waterbodies in Categories 2-4c (table 1) are not currently (2012) available from EPA. The TMDL dataset represents waters that are not supporting their designated uses. The 303(d) impaired waters and TMDL datasets have additional attributes maintained in separate tables inside their respective geodatabases. The spatial representation and descriptive attribute tables can be related (linked) using an associated identifier. These relationships are defined in the WQIS database.

\section{Data Acquisition and Preparation}

Updating the WQIS requires downloading all the requisite geospatial datasets, performing the GIS processing, and importing the new tables into the existing WQIS database. The updated version of the database or the reports produced by the database can then be made available to other users.

Requirements for successful data preparation include:

- ArcGIS (ESRI, Inc., Redlands, Calif.) suite of GIS products

- Microsoft Access (Microsoft Corporation, Seattle, Wash.)

- Datasets described in the Required Geospatial Datasets section (table 3)

It is assumed that a user attempting to refresh the data developed for the WQIS is familiar with GIS and database utilization, specifically the ArcGIS suite of products, and Microsoft Access. Methods described herein utilize ArcGIS 10.0 and Access 2010, but could be performed using other software packages.

The WQIS requires several datasets described in the Required Geospatial Datasets section. It is advisable to

Table 3. Geospatial datasets and their sources used to summarize water-quality issues on National Wildlife Refuges.

\begin{tabular}{|c|c|c|}
\hline Dataset & Online Linkage ${ }^{1}$ & Description \\
\hline FWS cadastral & http://www.fws.gov/GIS/data/CadastralDB/index.htm & $\begin{array}{l}\text { Datasets representing U.S. Fish and Wildlife Service } \\
\text { Approved, Interest and Special Designation layers. }\end{array}$ \\
\hline 303(d) impaired waters & http://epamap32.epa.gov/radims/ & $\begin{array}{l}\text { Datasets representing Clean Water Act Section 303(d) } \\
\text { impaired waters of the United States. }\end{array}$ \\
\hline
\end{tabular}

${ }^{1}$ Links valid as of September 1, 2012. 
develop a file location to maintain all datasets downloaded for this project. This will help maintain the integrity of the datasets as originally downloaded and provide a backup copy of the data should mistakes occur during the processing steps.

Many spatial analysis operations can be performed by using several, slightly different methods. This manual presents one method, but this method could be altered and still provide the same results. Naming conventions for datasets, especially those created during the spatial overlay data processing, have been suggested throughout the manual. Some suggestions are simply a matter of keeping track of the processing step(s) and are not necessary to duplicate; however, the final tables imported into the WQIS database MUST be given the specific names provided or the database queries will not function properly.

Download and save the FWS Cadastral Geodatabase (fig. 1) from http://www.fws.gov/GIS/data/CadastralDB/index. htm (U.S. Fish and Wildlife Service, 2012b) by clicking on the FWS Cadastral Geodatabase link. These data provide the necessary spatial representations of refuge boundaries. Make note of the date on which the data were updated and published (fig. 1). This information will be needed during the refresh of the WQIS database.
Download the NHDPlus, National Hydrography Dataset for each of the regions within the contiguous United States and Hawaii (regions 1-18 and 20) from http://www.horizonsystems.com/nhdplus/index.php (Horizon Systems Corporation, 2012) by clicking on the NHDPlus Version 1 (Archive) link (fig. 2). These data provide a stream centerline network based on the medium resolution $(1: 100,000)$ NHD. Click on the Data link on the NHDPlus Version 1 (Archive) Web site (fig. 3). Click on a NHD region (fig. 4) to view all the available datasets for that region (fig. 5). The only dataset required for this analysis is the National Hydrography Dataset (see example in fig. 5).

Obtain the EPA water-quality datasets from $h t t p: / /$ epamap32.epa.gov/radims/ (U.S. Environmental Protection Agency, 2012) by clicking on the National Geospatial Datasets Extractions link (figs. 6 and 7). Download the ESRI File Geodatabase for both the 303(d) listed impaired waters and TMDLs (fig. 8). These datasets provide line segments representing impaired waters, impaired waters with established TMDLs, and the associated parameter attribute tables. Make note of the extraction date for the EPA water-quality data (fig. 8). This information will be needed during the refresh of the WQIS database.

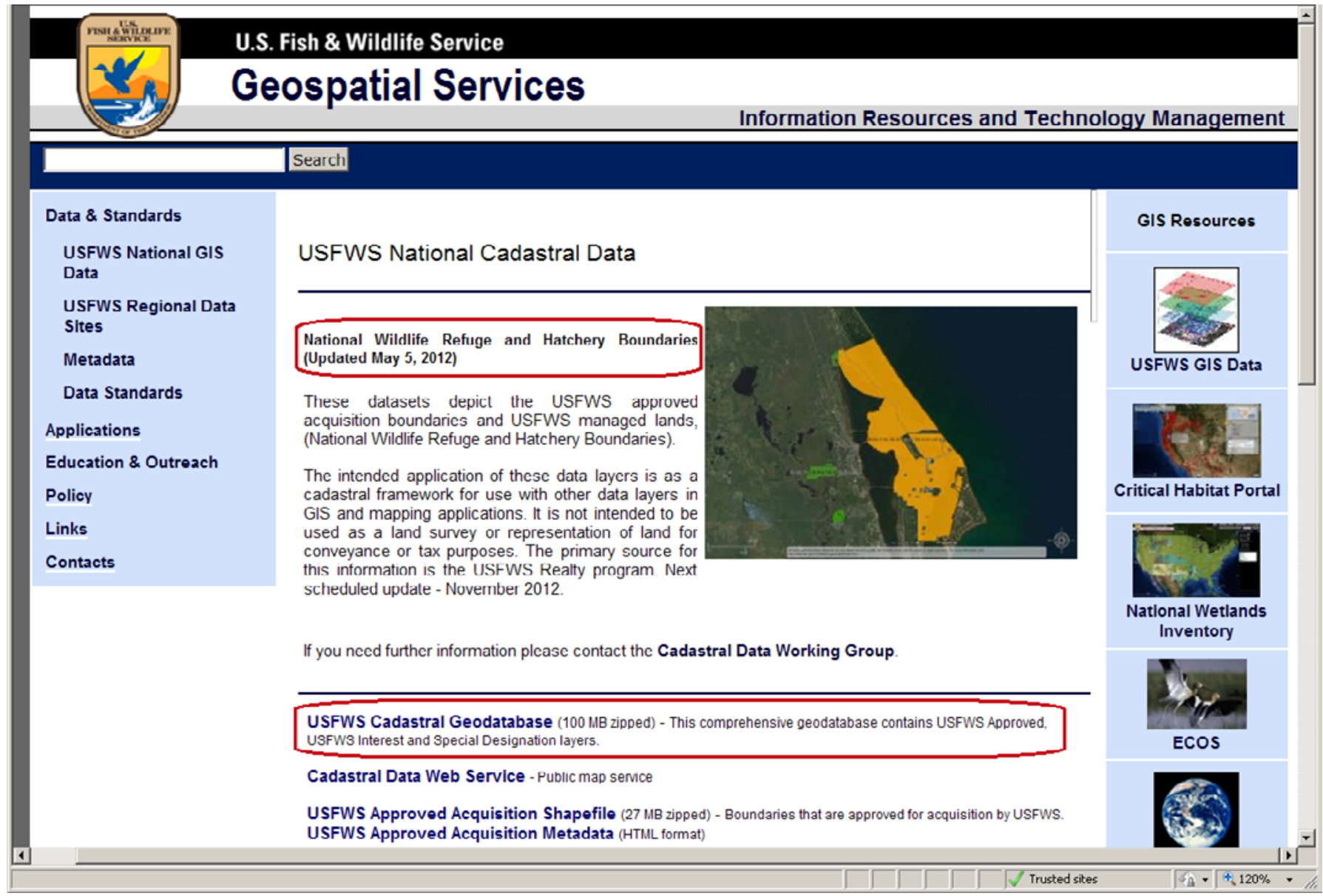

Figure 1. Screen capture of the U.S. Fish and Wildlife Service Geospatial Services webpage (May 22, 2012). 


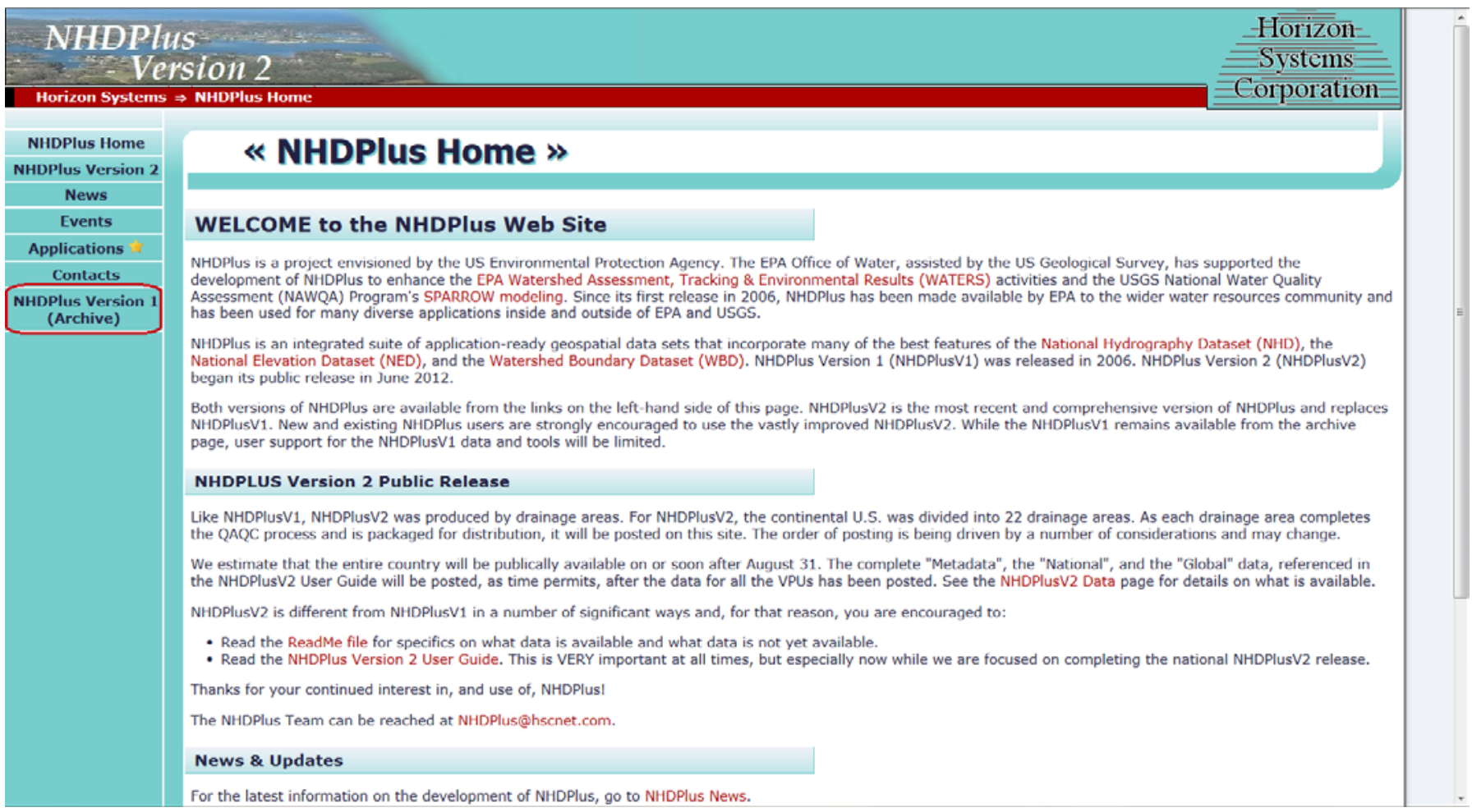

Figure 2. Screen capture of the NHDPlus Web site showing the NHDPlus Data link (November 1, 2012).

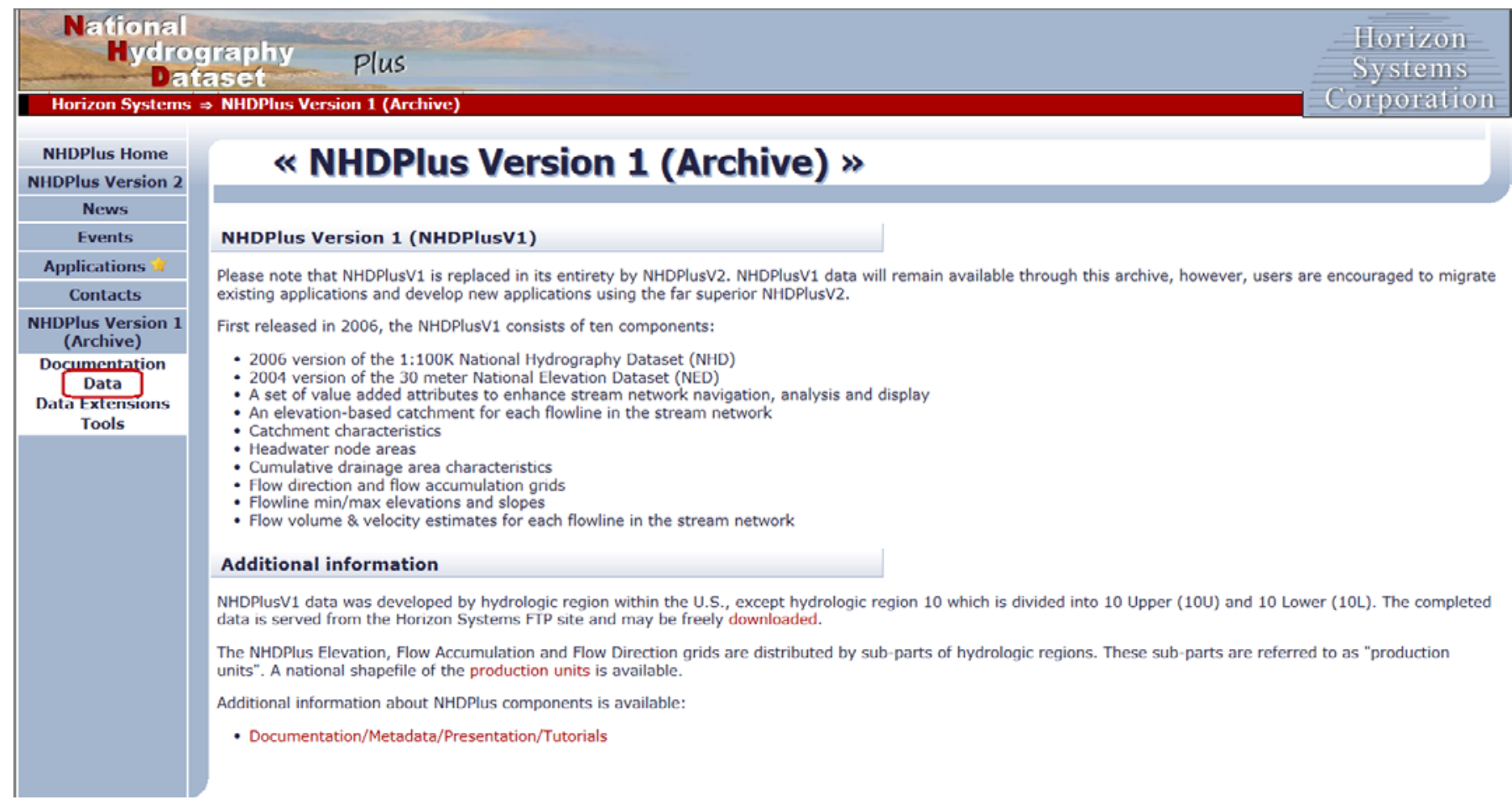

Figure 3. Screen capture of the NHDPlus Version 1 archive Web site (November 1, 2012). 


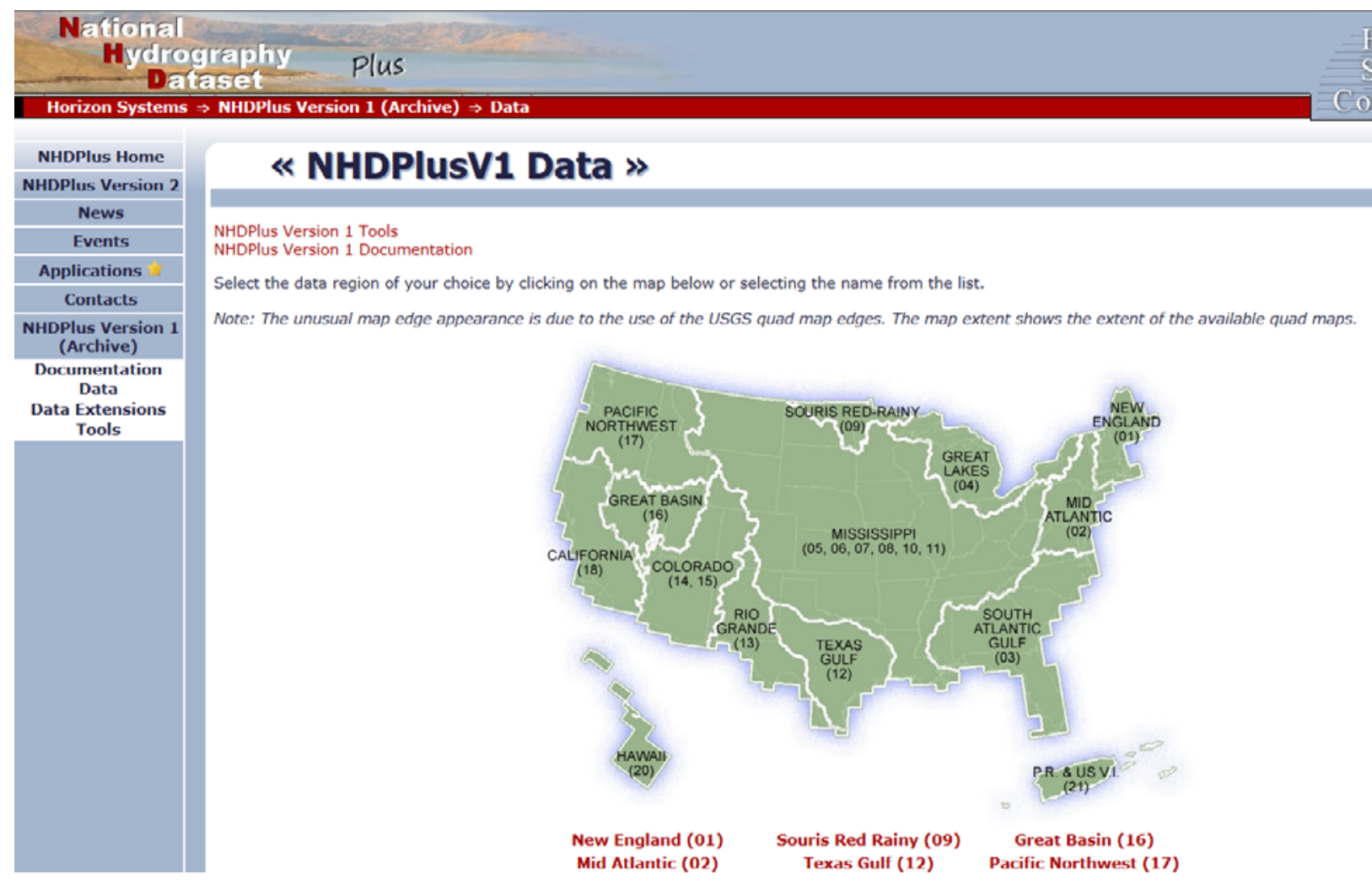

Figure 4. Screen capture of the NHDPlus regions (November 1, 2012).

\begin{tabular}{|c|c|c|}
\hline File Description & File Name (.zip***) & Format \\
\hline Region 01 , Version 01_01, Catchment Grid & NHDPlus01V01_01_Catgrid & ESRI Grid* \\
\hline Region 01, Version 01_01, Catchment Shapefile & NHDPlus01V01_01_Catshape & Shapefile** \\
\hline $\begin{array}{l}\text { Region 01, Version 01_02, Catchment Flowline } \\
\text { Attributes }\end{array}$ & NHDPlus01V01_02_Cat_Flowline_Attr & $\mathrm{r} \mathrm{DBF}^{* * * *}$ \\
\hline Region 01, Version 01_02, Elevation Unit a & NHDPlus01V01_02_Elev_Unit_a & ESRI Grid \\
\hline $\begin{array}{l}\text { Region 01, Version 01_01, Flow Accumulation and Flow } \\
\text { Direction Unit a }\end{array}$ & NHDPlus01V01_01_FAC_FDR_Unit_a & ESRI Grid \\
\hline $\begin{array}{l}\text { Region 01, Version 01_01, National Hydrography } \\
\text { Dataset }\end{array}$ & $\underline{\text { NHDPlus01V01 } 03 \mathrm{NHD}}$ & $\begin{array}{l}\text { Shapefile and } \\
\text { DBF }\end{array}$ \\
\hline Region 01, Version 01_01, QAQC \& Sinks Spreadsheet & NHDPlus01V01_01_QAQC_Sinks & $\begin{array}{l}\text { Excel } \\
\text { Spreadsheet }\end{array}$ \\
\hline Region 01, Version 01_01, Stream Gage Event & NHDPlus01V01_01_StreamGageEvent & $\mathrm{DBF}$ \\
\hline
\end{tabular}

Figure 5. Screen capture of the NHDPlus version 1 datasets. The National Hydrography Dataset needed for the Water Quality Information System analysis is circled in red (November 1, 2012). 


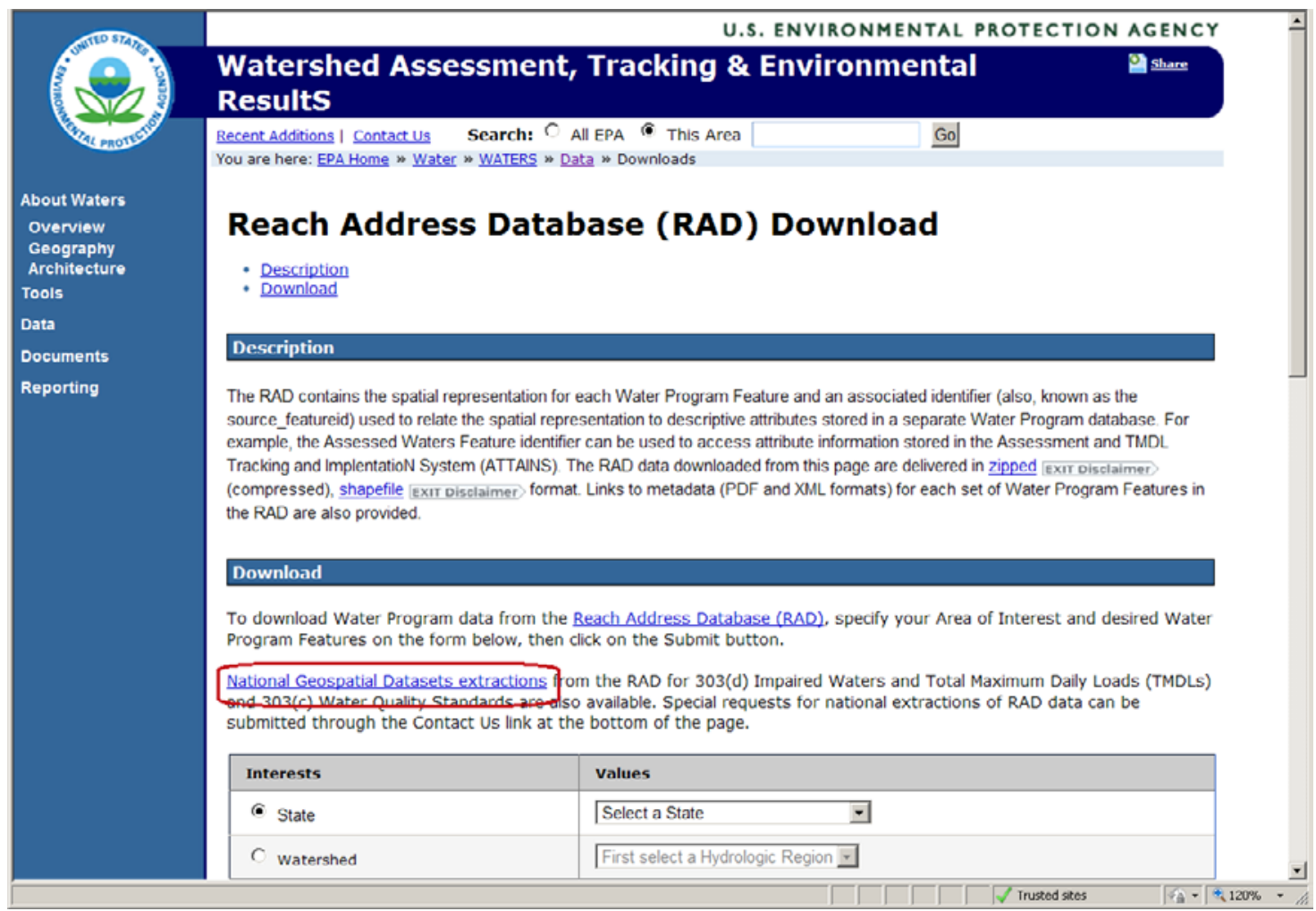

Figure 6. Screen capture of the U.S. Environmental Protection Agency Reach Address Database Download Web site. The National Geospatial Datasets extractions web link is circled in red (May 22, 2012).

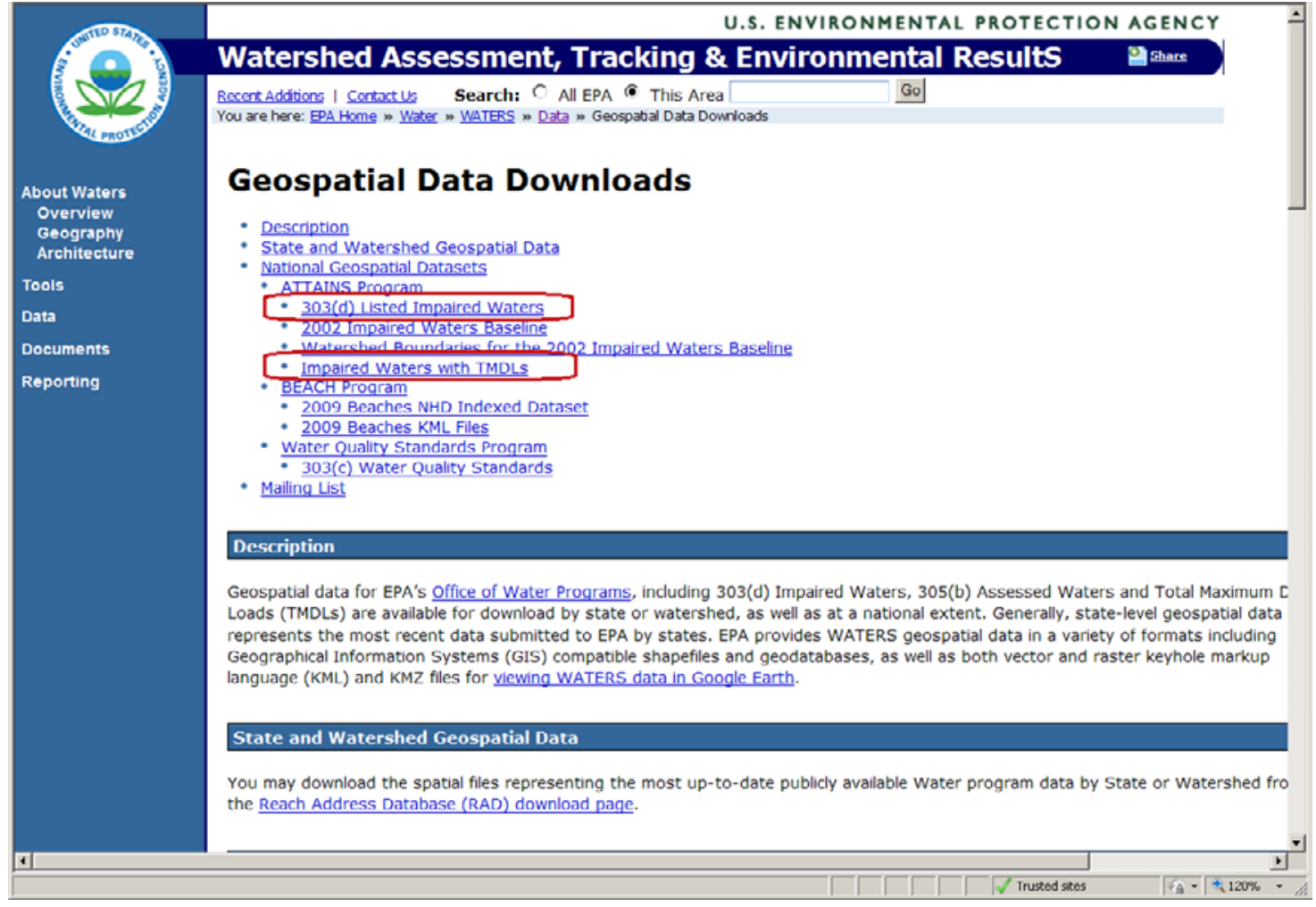

Figure 7. Screen capture of the National Geospatial Datasets webpage. The web links to download the Clean Water Act Section 303(d) listed impaired waters and impaired waters with total maximum daily load datasets are circled in red (May 22, 2012). 


\begin{tabular}{|c|c|}
\hline \multicolumn{2}{|c|}{ 303(d) Listed Impaired Waters NHD Indexed Dataset } \\
\hline Download & Shapefiles (156 MB) \\
\hline Extracted on May 3, 2012 & ESRI 9.3.1 File Geodatabase (111 MB) \\
\hline Changelog (Excel)(17K) & Attributes Only (Excel, $7.5 \mathrm{MB}$ ) \\
\hline Metadata & Metadata is located within the downloads and at the EPA Environmental Dataset Gateway. \\
\hline Additional Information & $\begin{array}{l}\text { Fact Sheet ( } \mathrm{pdf})(2 \mathrm{pp}, 473 \mathrm{~K}) \\
\text { Attribute Field Descriptions (Word)( } 2 \mathrm{pp}, 22 \mathrm{~K})\end{array}$ \\
\hline $\begin{array}{l}\text { Geospatial and Attribute Linkage } \\
\text { Information }\end{array}$ & $\begin{array}{l}\text { Use the provided ESRI_KEY for joining tables. Note that there is a many-to-many relationship between attributes and geospatial } \\
\text { records. }\end{array}$ \\
\hline
\end{tabular}

Figure 8. Screen capture of the Clean Water Act Section 303(d) Listed Impaired Waters Download webpage. The link to download the ESRI File Geodatabase is circled in red (May 22, 2012).

The FWS Cadastral, NHDPlus, and EPA water-quality datasets are downloaded as compressed zip files. Unzip each downloaded dataset using WinZip (WinZip Computing, Mansfield, Conn.) or similar software.

\section{Spatial Overlay}

Spatial overlay will be used to extract NHD stream segments, 303(d) impaired waters, and waters with established TMDLs within refuge boundaries. It is advisable to create a new geodatabase to contain the data layers created to refresh the WQIS database.

Open ArcCatalog and create a File Geodatabase by right clicking on the folder where the new file geodatabase will be created, click New, click File Geodatabase (fig. 9), and name the new geodatabase WaterQuality.

\section{Prepare the Analysis Areas File}

In an ArcMap map document, add the FwsApproved and FwsInterest data layers from the FwsCadastral.gdb, FwsBoundary Feature Dataset (fig. 10).

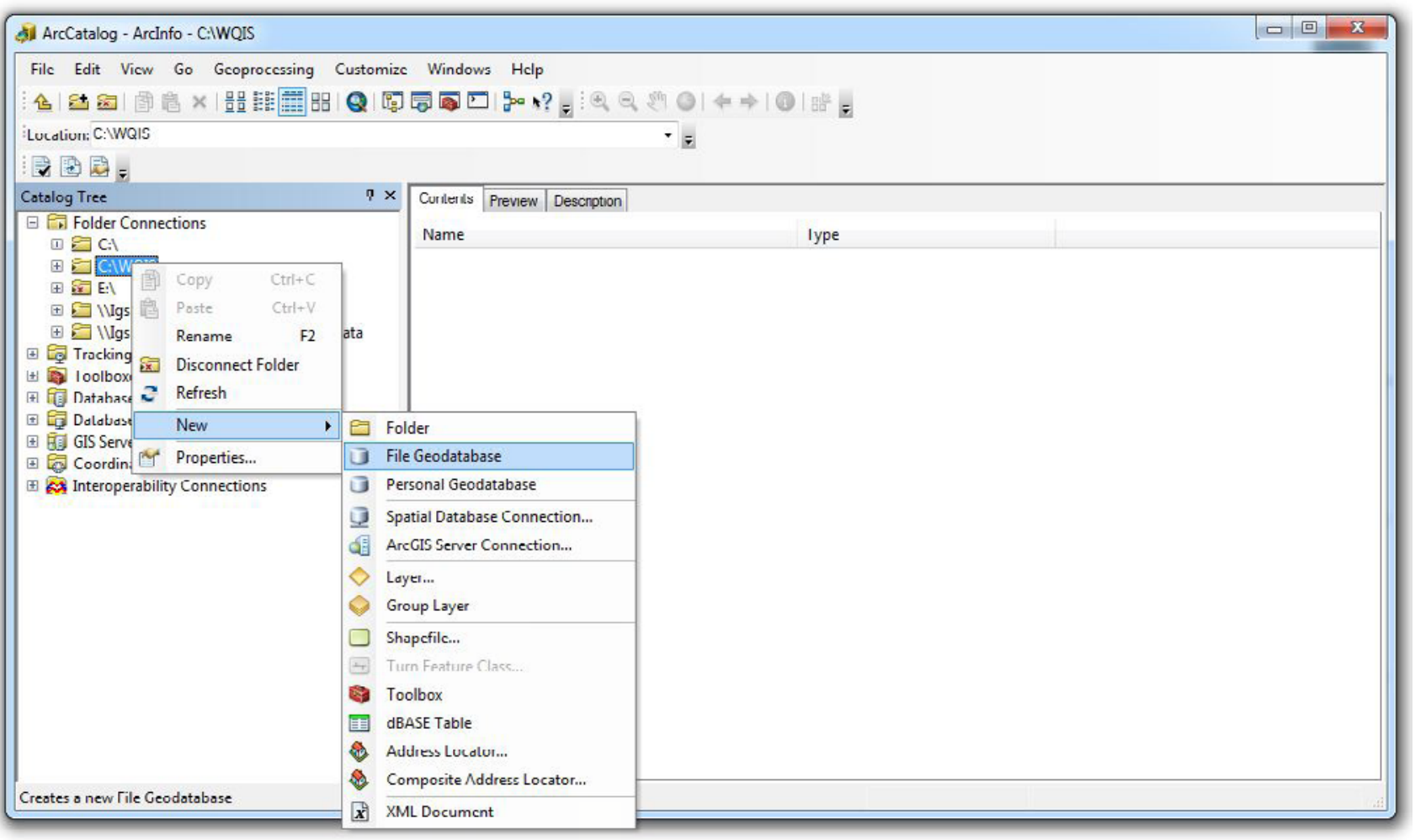

Figure 9. Screen capture showing the creation of a new file geodatabase in ArcCatalog. 


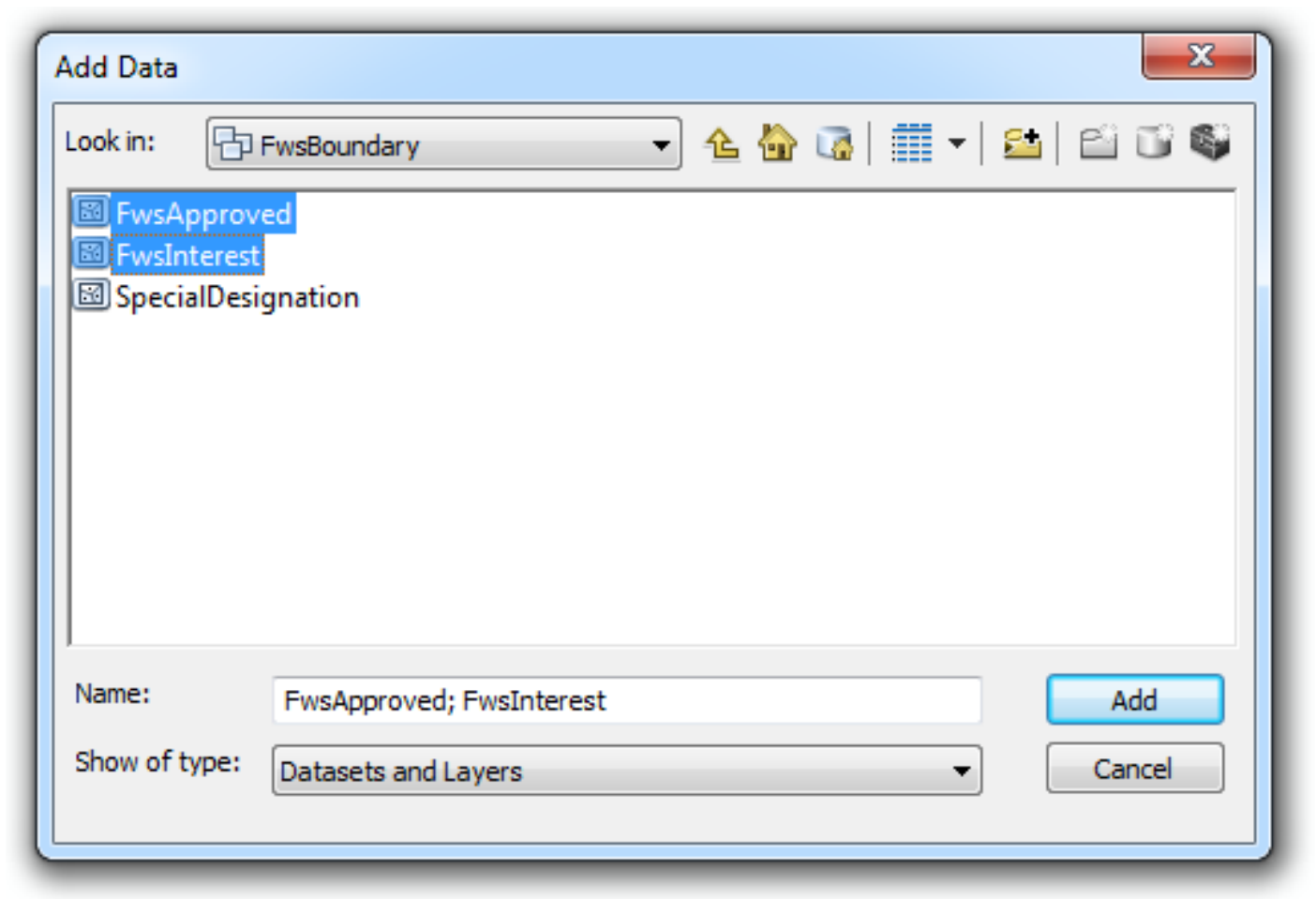

Figure 10. Screen capture of adding the FwsApproved and FwsInterest data layers to ArcMap.

To filter the FwsApproved boundaries layer to display only National Wildlife Refuges, open the FwsApproved layer properties, click on the Definition Query tab, and use the Query Builder to create the following expression: "RSL_ TYPE" = 'NWR' (fig. 11).

The FwsApproved layer contains four large and inclusive refuges (Dakota Grassland, Driftless Area, Northern Tallgrass Prairie, and Silvio O. Conte). These refuges span multiple States and overlap with other refuge boundaries (for example, Agassiz, Big Stone, and Rydell Refuges are included within the Northern Tallgrass Prairie NWR boundary). This overlap would result in double counting streams and impaired waters that are within both boundaries (for example, stream length would be summarized once for Agassiz NWR and once for Northern Tallgrass Prairie NWR, which would account for the stream length inside Agassiz twice when summarized for the region and Nation). To address this issue, the approved boundaries for Dakota Grassland, Driftless Area, Northern Tallgrass Prairie, and Silvio O. Conte need to be replaced with boundaries from the FwsInterest dataset so that they would not be included in the data analysis. This process is accomplished by

Figure 11. Screen capture of the Query Builder expression used to display only National Wildlife Refuges. creating an Analysis Area data layer as documented in the following paragraphs.

To prepare an Analysis Areas data layer, click Selection, click Select By Attributes, and ensure that the FwsApproved layer is selected in the Layer dropdown menu (fig. 12). Select all NWR's EXCEPT Dakota Grassland, Driftless Area, Northern Tallgrass Prairie, and Silvio O. Conte using the following expression: "ORGNAME" NOT IN ('DAKOTA GRASSLAND CONSERVATION AREA', 'DRIFTLESS

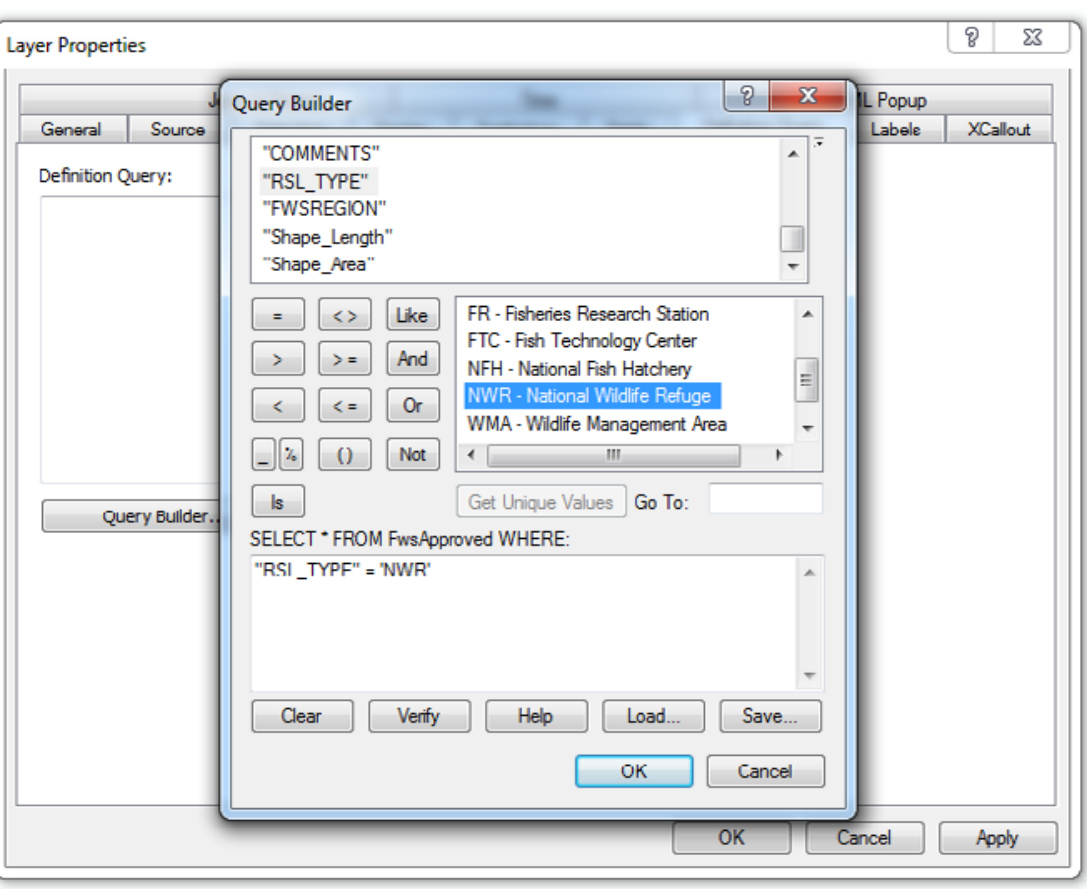




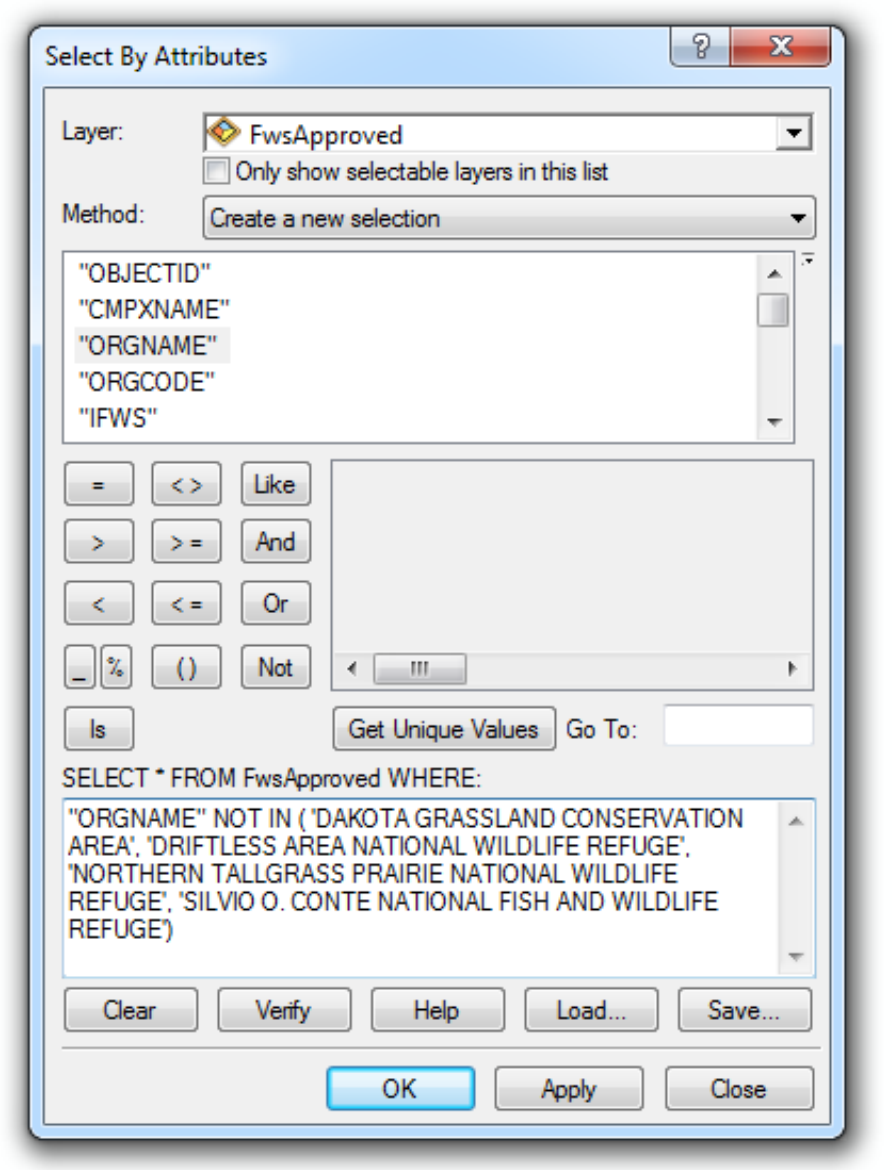

Figure 12. Screen capture of the Select by Attributes tool used to select the approved boundaries for all Refuges EXCEPT the four large Refuges in the FwsApproved data layer.

\section{AREA NATIONAL WILDLIFE REFUGE', 'NORTHERN} TALLGRASS PRAIRIE NATIONAL WILDLIFE REFUGE', 'SILVIO O. CONTE NATIONAL FISH AND WILDLIFE REFUGE') (fig. 12). Tip: copy and paste the expression into the expression box.

Next click Selection, click Select By Attributes, and ensure that the FwsInterest layer is selected in the Layer dropdown menu. Select the four NWR's named above using the following expression: "ORGNAME" IN ('DAKOTA GRASSLAND CONSERVATION AREA', 'DRIFTLESS AREA NATIONAL WILDLIFE REFUGE', 'NORTHERN TALLGRASS PRAIRIE NATIONAL WILDLIFE REFUGE', 'SILVIO O. CONTE NATIONAL FISH AND WILDLIFE REFUGE') (fig. 13).

Use the Merge tool (in ArcToolbox, Data Management Tools, General) to combine the selected areas from both the FwsApproved and FwsInterest data layers, producing the Analysis Areas data layer. Select the FwsApproved and FwsInterest data layers as the Input Datasets, and define the Output Dataset as Analysis Areas in the newly created WaterQuality geodatabase (fig. 14). The "Analysis Areas" name is not required; it is simply a means of keeping track of datasets created during the spatial overlay analysis process. Examine the new boundary layer to ensure the results are as expected.
The geospatial boundaries of the FWS Cadastral data may change with time, making it necessary to reevaluate the refuges included during this step of the spatial overlay analysis. The above procedure can be modified at any time to include or exclude certain properties or types of properties to suit the needs of the users.

\section{Prepare NHDPlus Flowlines Dataset}

To maintain manageable datasets, ArcGIS will be used to clip the NHD flowlines for each region to the extent of areas within the Analysis Areas data layer (from the Prepare the Analysis Areas File section) before assembling the NHD flowlines from each NHDPlus region into one national dataset. The clipped NHD flowlines will then be merged into one dataset representing only NHD flowlines within the Analysis Areas defined for this project.

Add the NHDflowline dataset for each of the National Hydrography Dataset region (1-18 and 20) files to the ArcMap document. The NHDflowline datasets can be found in the Hydrography folder (fig. 15) once the zip files have been extracted.

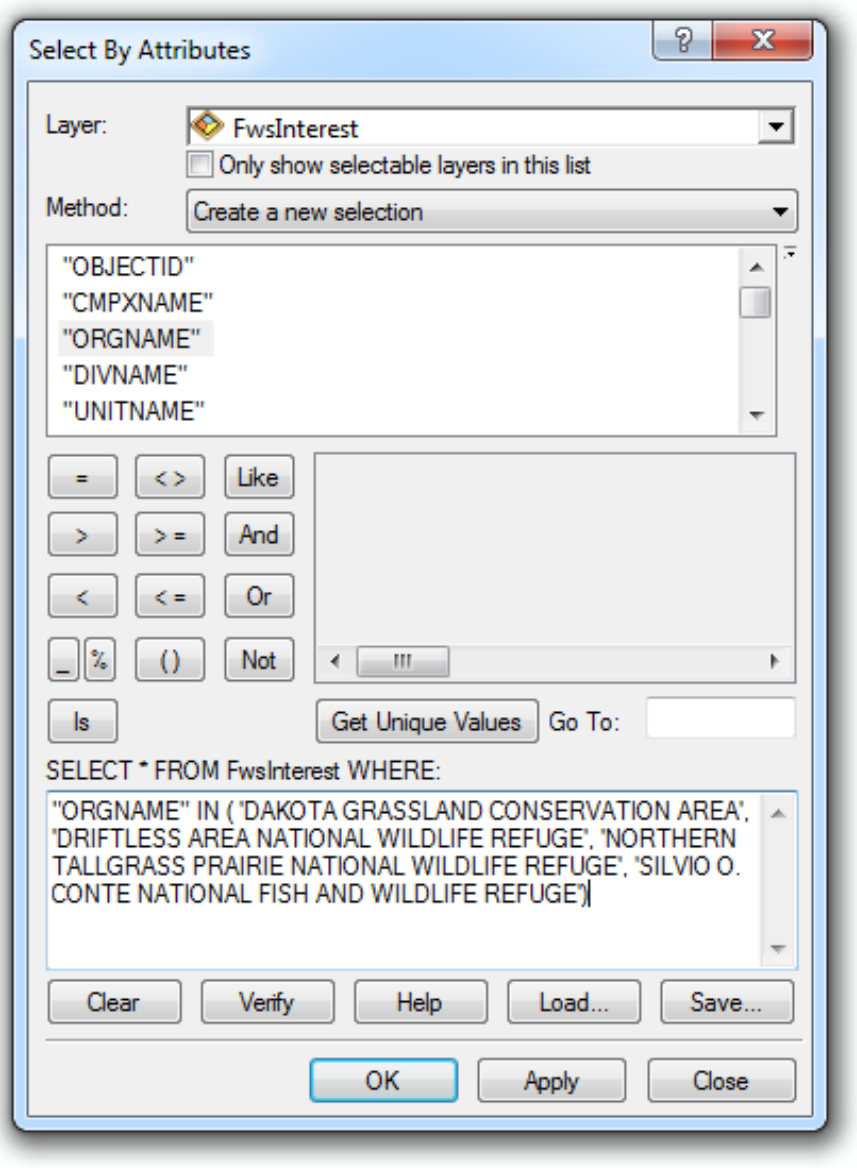

Figure 13. Screen capture of the Select by Attributes tool used to select the boundaries of the four Refuges in the FwsInterest data layer. 


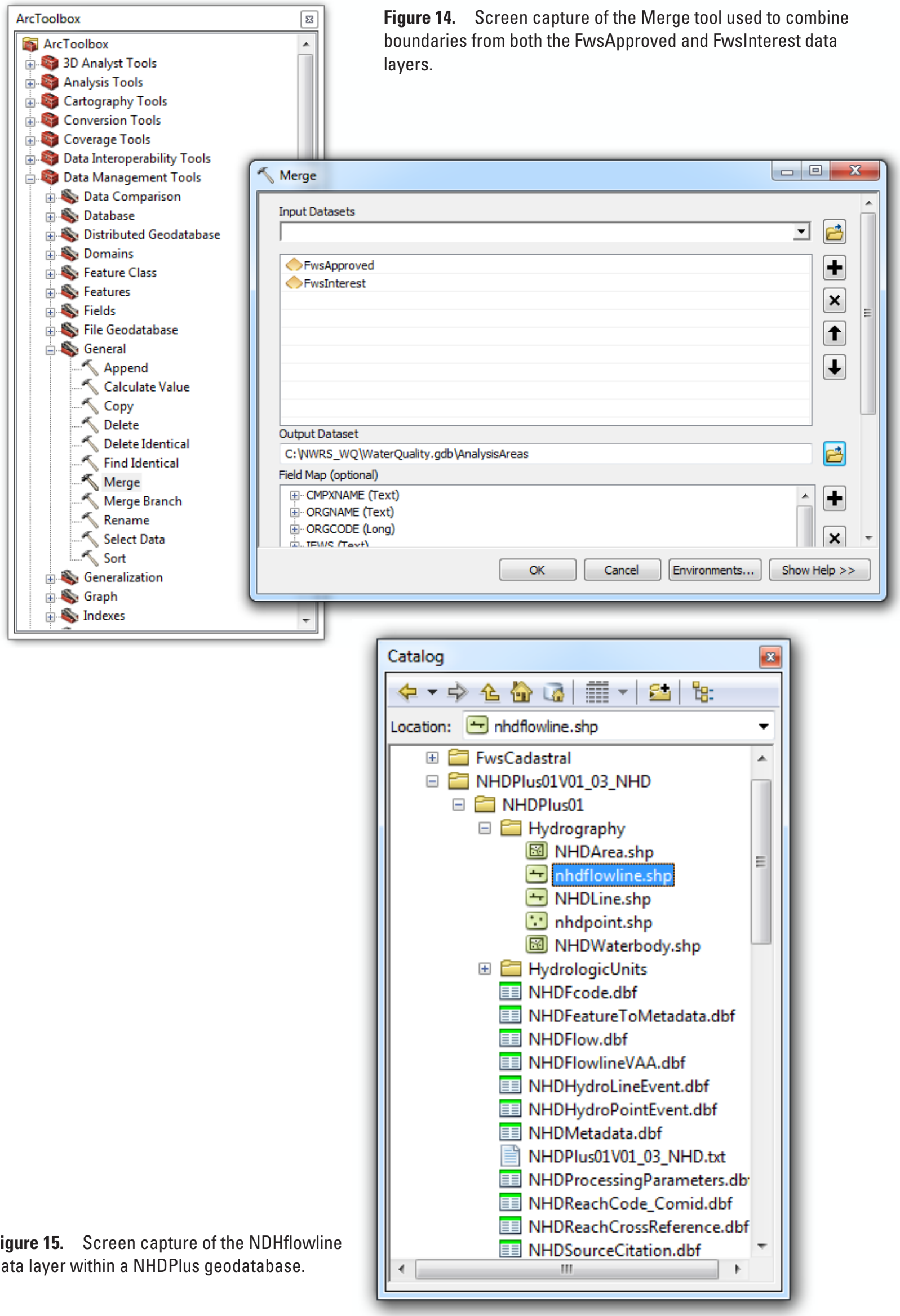


Use the Clip tool from the ArcToolbox, Analysis Tools, Extract toolset to clip the NHDflowlines from each particular NHD region (1-18 and 20) to the extent of the refuge boundaries within the Analysis Areas data layer (fig. 16). The clip procedure must be repeated for each of the regions. Clipping the NHDflowlines of each NHD region prior to combining the flowlines into one large data layer for overlay with the Analysis Areas data layer reduces the processing time by limiting the number of unnecessary features in the overlay analysis. Tip: ArcGIS ModelBuilder can be used to expedite this repetitive task.

Once the NHDflowlines from each NHD region have been clipped to include only flowlines within refuge boundaries, use the Merge tool in the ArcToolbox, Data Management Tools, General toolset to combine all the clipped NHD files into one NHDflowline dataset (fig. 17). Name this data layer NHDflowlines_NWRS and save it into the WaterQuality geodatabase.

A Spatial Join will be utilized to join important attributes from the Analysis Areas data layer (for example, refuge name) to the NHDflowlines data layer. Right click on the merged NHD flowline data layer in the ArcMap table of contents, select Joins and Relates, then select Joins. Select "Join data from another layer based on spatial location", choose the Analysis Areas as the layer you wish to join, select the "each line will be given all the attributes of the polygon that it falls completely inside" option (fig. 18). Name the new data layer NHDflowline_NWRS_Join and save it to the WaterQuality geodatabase.

Several unnecessary fields are added to the NHDflowline dataset during processing. These extra fields can cause confusion and even errors in the final database if they are not removed before importing the resultant data into the WQIS database. Open the attribute table for the newly created NHDflowline NWRS Join data layer. Delete the fields named LENGTHKM, and SHAPE LENG by right clicking the field column name and selecting Delete Field. Use caution during this step as deleting columns cannot be undone.

All stream-segment records must have a value in the GNIS_Name column to be properly parsed by the WQIS database ("null" values must be replaced). With the NHDflowline_NWRS_Join attribute table open, select records with "null" value in the GNIS_Name column by clicking Select By Attributes under the Table Options menu, then enter the following expression: "GNIS_NAME" =" (fig. 19).

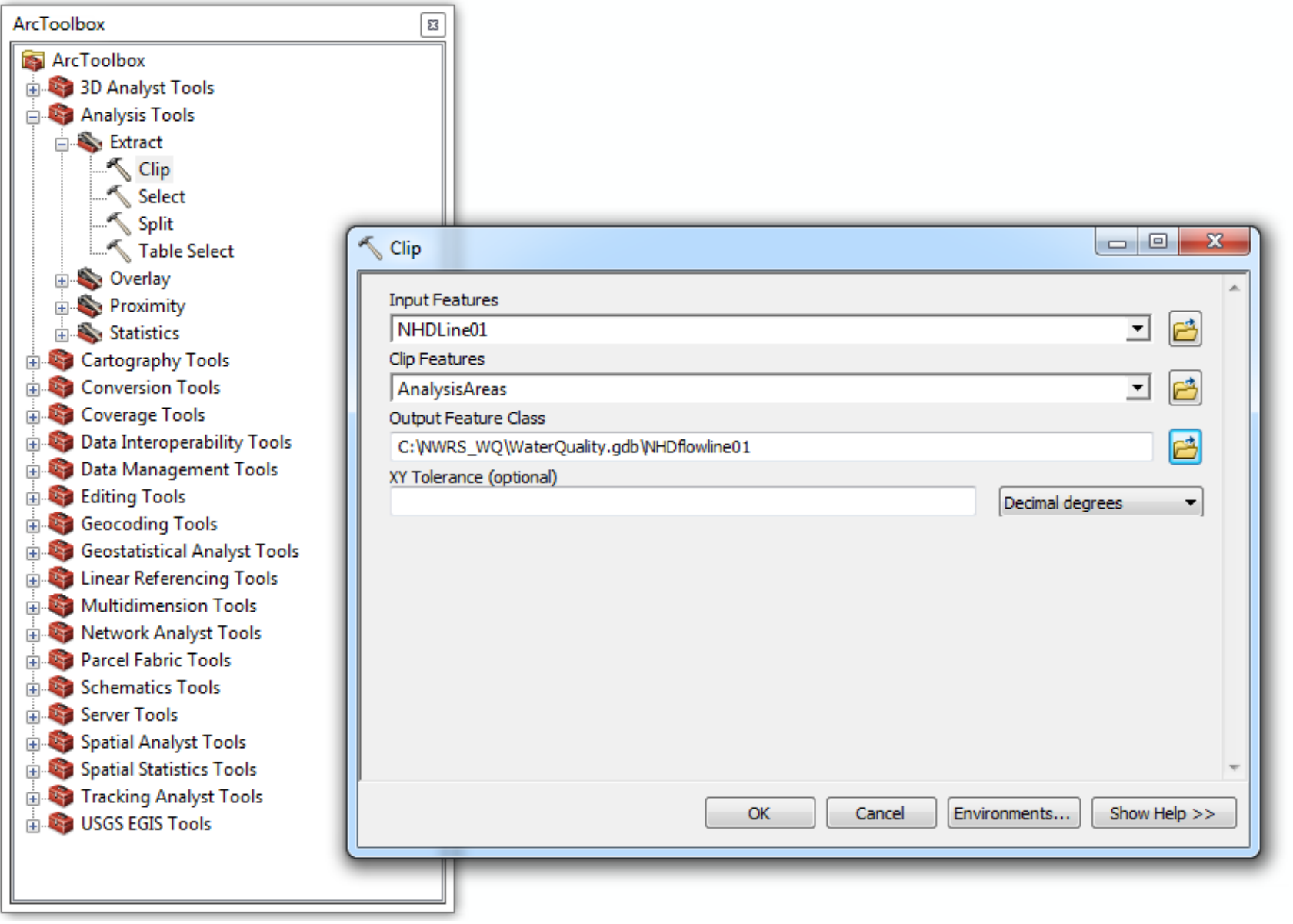

Figure 16. Screen capture of the Clip tool used to clip the NHDflowlines from each National Hydrography Dataset region to refuge boundaries using the Analysis Areas data layer created previously. 


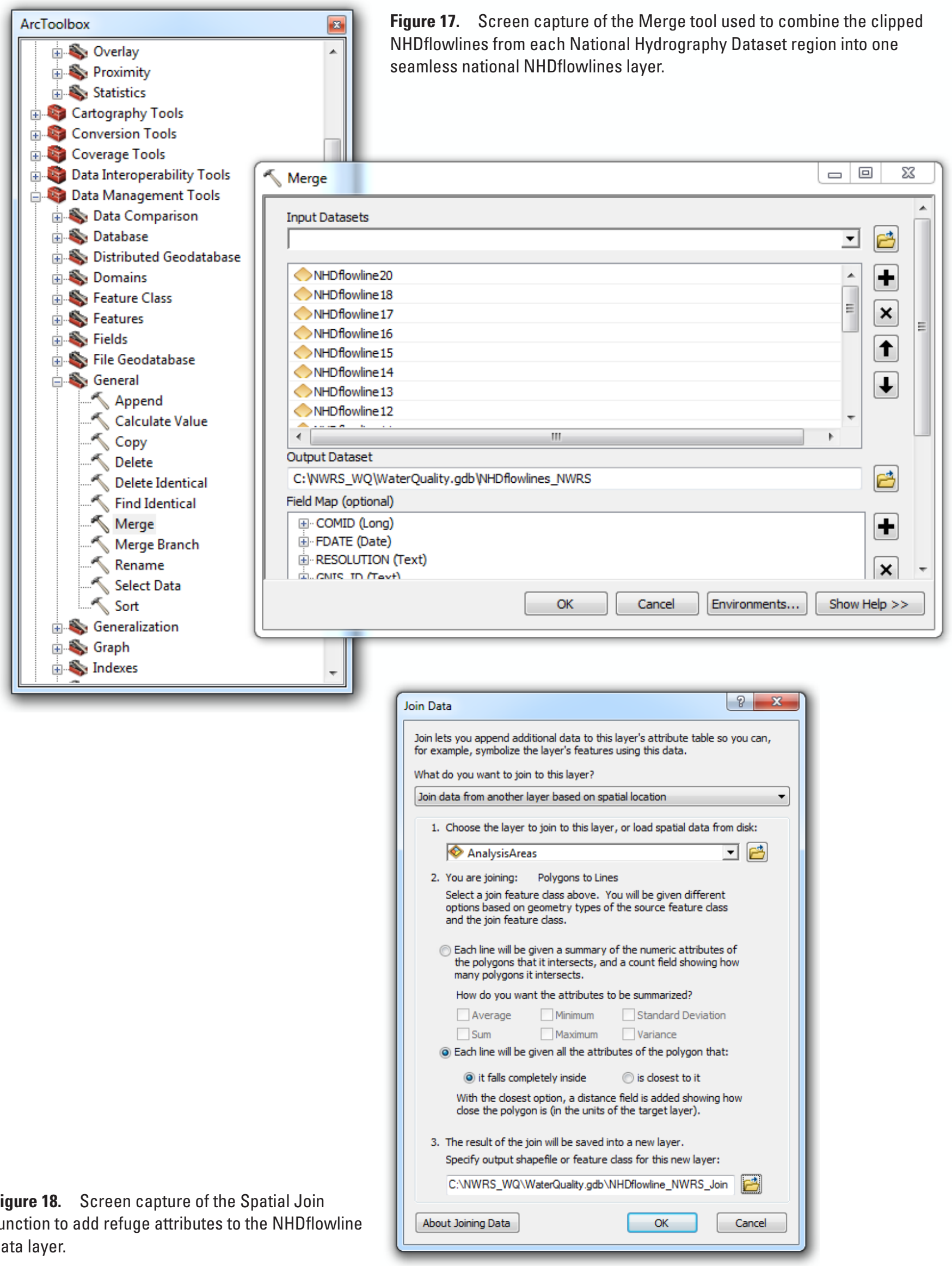




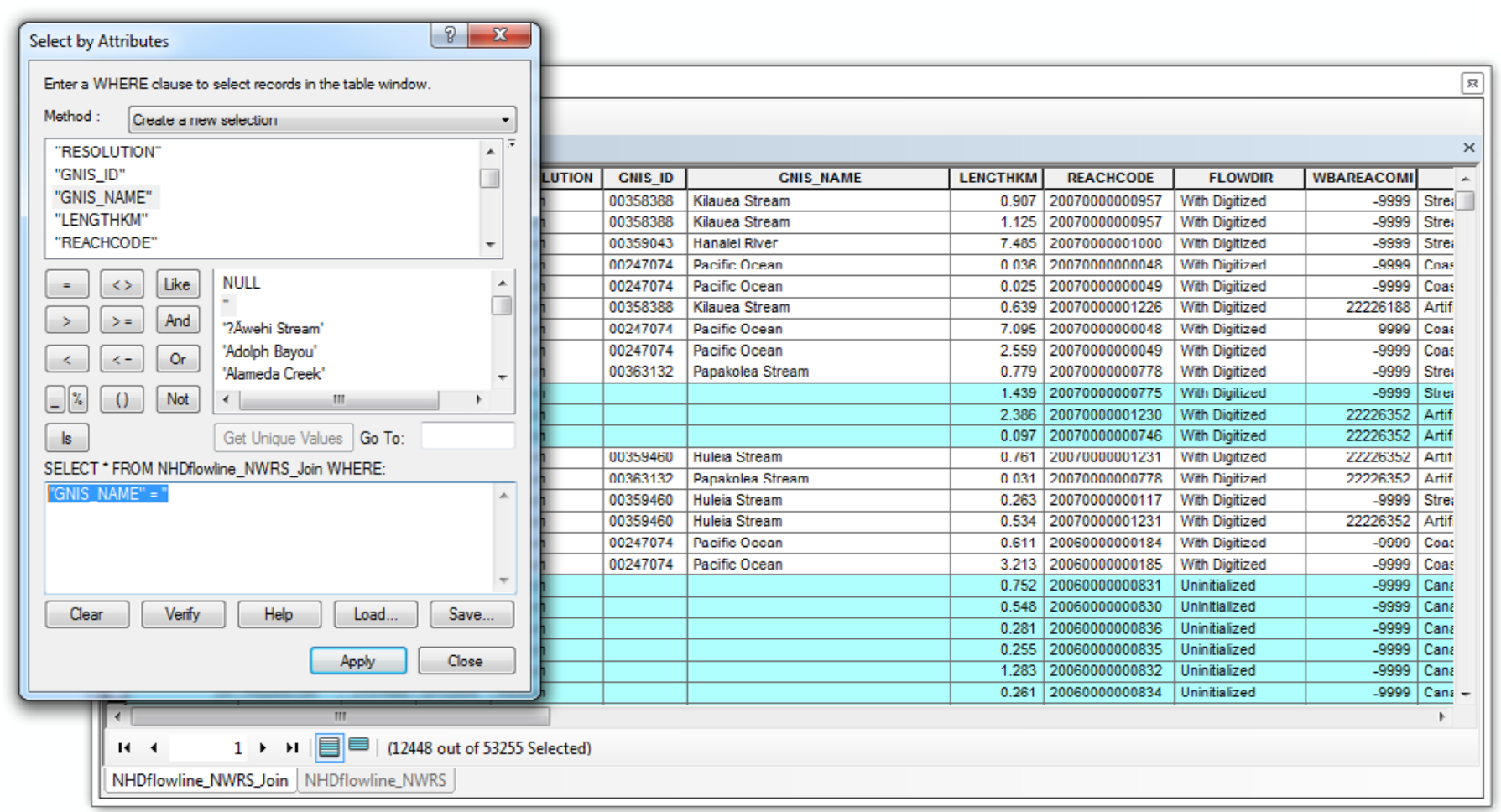

Figure 19. Screen capture of the Select by Attributes tool used to select stream segments with null values in the GNIS_Name column.

Use the Field Calculator to populate these records with "Unnamed stream(s)", by right clicking on the "GNIS NAME" field, then clicking on Field Calculator, and entering "Unnamed stream(s)" as the expression.

The NHDflowline datasets contain line segments representing features that are outside the scope of the WQIS (artificial path, coastline, and pipeline). To eliminate these features from the WQIS, open the NHDflowline_NWRS_Join layer properties, click on the Definition Query tab, and use the Query Builder to create the following expression to eliminate the artificial path, coastline, and pipeline line segments: "FTYPE" NOT IN ('ArtificialPath', 'Coastline', 'Pipeline') (fig. 20). Artificial path line-segments represent flow through an open waterbody, such as a lake, to facilitate hydrologic

Figure 20. Screen capture of the Query Builder expression used to eliminate artificial path, coastline, and pipeline features from the NHDflowline dataset representation in ArcMap. modeling (NHDplus Team, 2010). Coastline is defined as a contact line between the open sea and the land. Pipeline is defined as a closed conduit for long-distance transport of gases, fluids or finely divided solids.

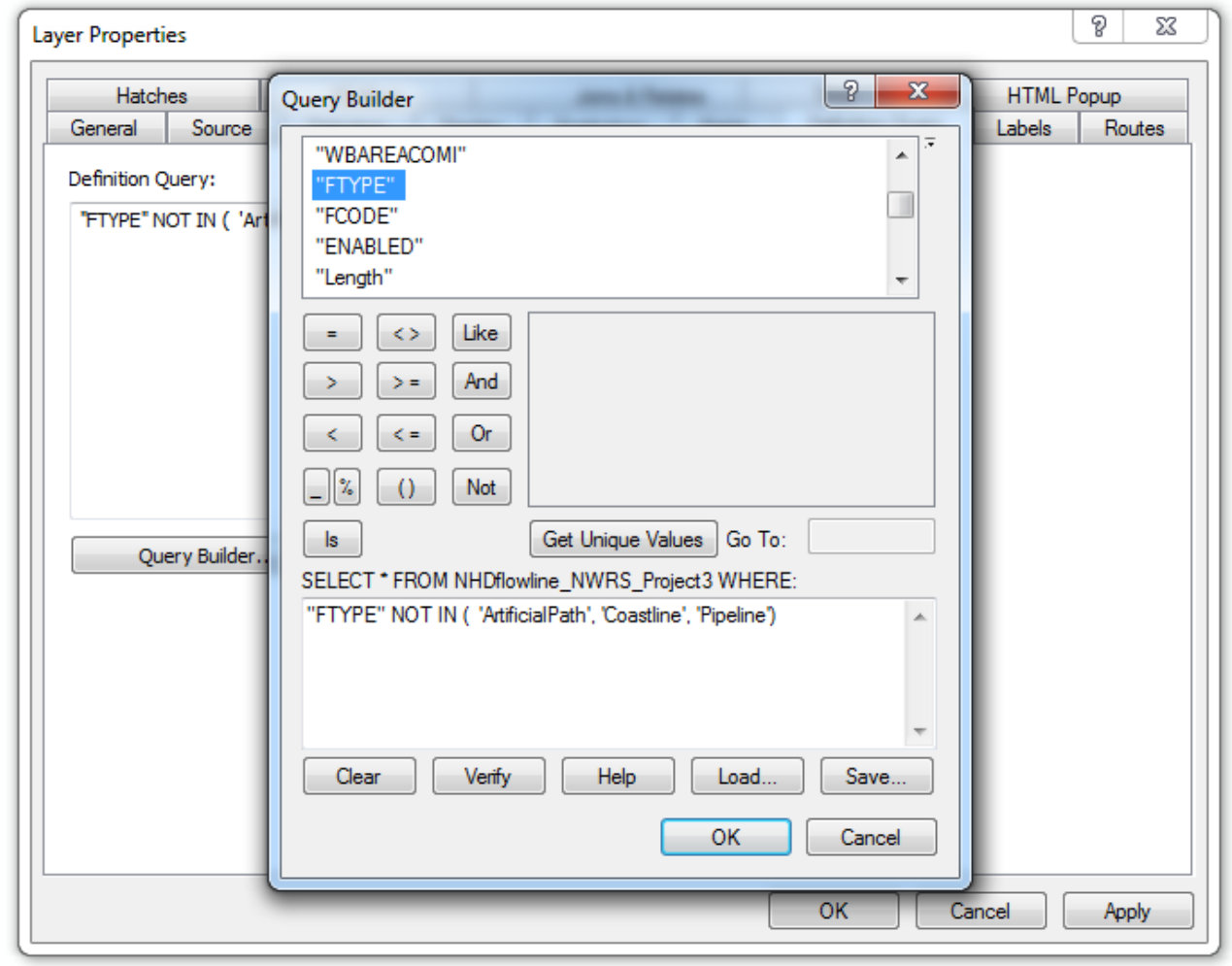




\section{Prepare the Water-Quality Datasets}

In the ArcGIS map document, add the impaired waters data layer by navigating to the rad_303d geodatabase, then add the rad_303d_1 feature class. Add the TMDL data layer by navigating to the Rad_impwtmdl geodatabase, then adding the rad_impwtmdl_1 feature class. Use the Clip tool from the ArcToolbox, Analysis Tools, Extract toolset to clip the 303(d) listed impaired waters and TMDL datasets to the boundaries of the Analysis Areas data layer. The layers can be named Impaired_NWRS and TMDL_NWRS respectively and saved to the WaterQuality geodatabase.

\section{Reproject the NHD Flowlines and Water-Quality Datasets}

The prepared NHD flowlines, 303(d) listed impaired waters, and TMDL datasets need to be converted to a projected coordinate system to calculate stream-segment length in meters. Use the Project or Batch Project tool from the Data Management Tools, Projections and Transformations toolbox (fig. 21) to convert the prepared datasets to a projected coordinate system. Select the North America Equidistant Conic projection file in the Projected Coordinate Systems,
Continental, North America folder. Name the layers NHDflowline_NWRS_Join_Project, Impaired_NWRS_Project, and TMDL_NWRS_Project, respectively, and save to the WaterQuality geodatabase.

\section{Export Tables}

The attribute table for each prepared data layer will need to be saved to a format that can be read by Microsoft Access. Open the attribute table for the prepared NHD flowlines (NHDflowlines_NWRS_Join_Project), 303(d) listed impaired waters (Impaired_NWRS Project), and TMDL (TMDL NWRS_Project) datasets and choose Export under the Table Options tab (fig. 22). When saving the tables, be sure to select dBASE table as the file type. Save each table as a .dbf file using the following table names; NHD.dbf, Impaired.dbf, and TMDL. $d b f$ (fig. 23). This naming convention must be followed for the WQIS database to function properly.

\section{Prepare the Parameter Attribute Tables}

Parameter data related to 303(d) impaired waters and TMDL datasets are maintained in separate tables developed and maintained by EPA. These tables also will need to be

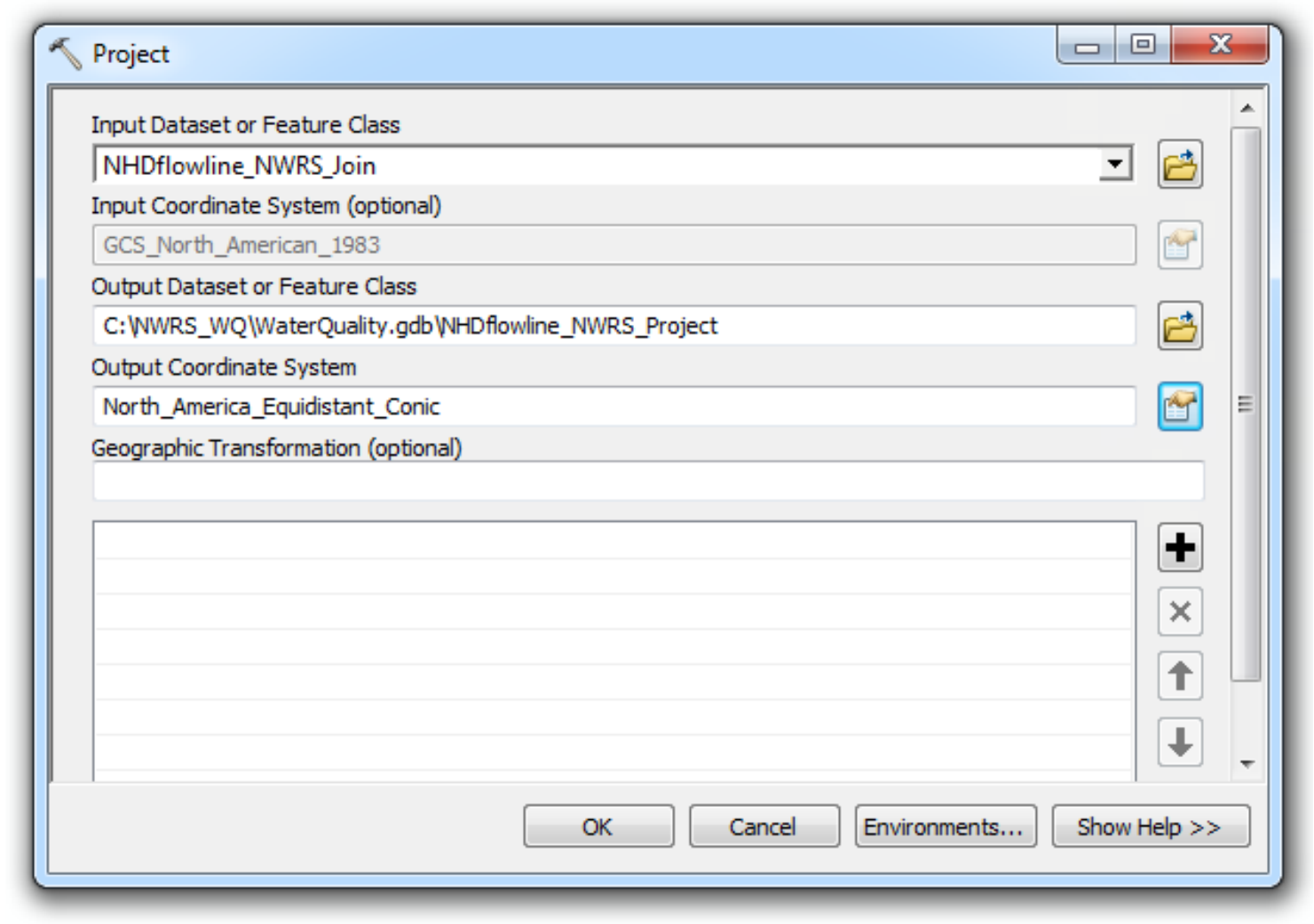

Figure 21. Screen capture of the Project tool used to convert the prepared datasets to a projected coordinate system. 


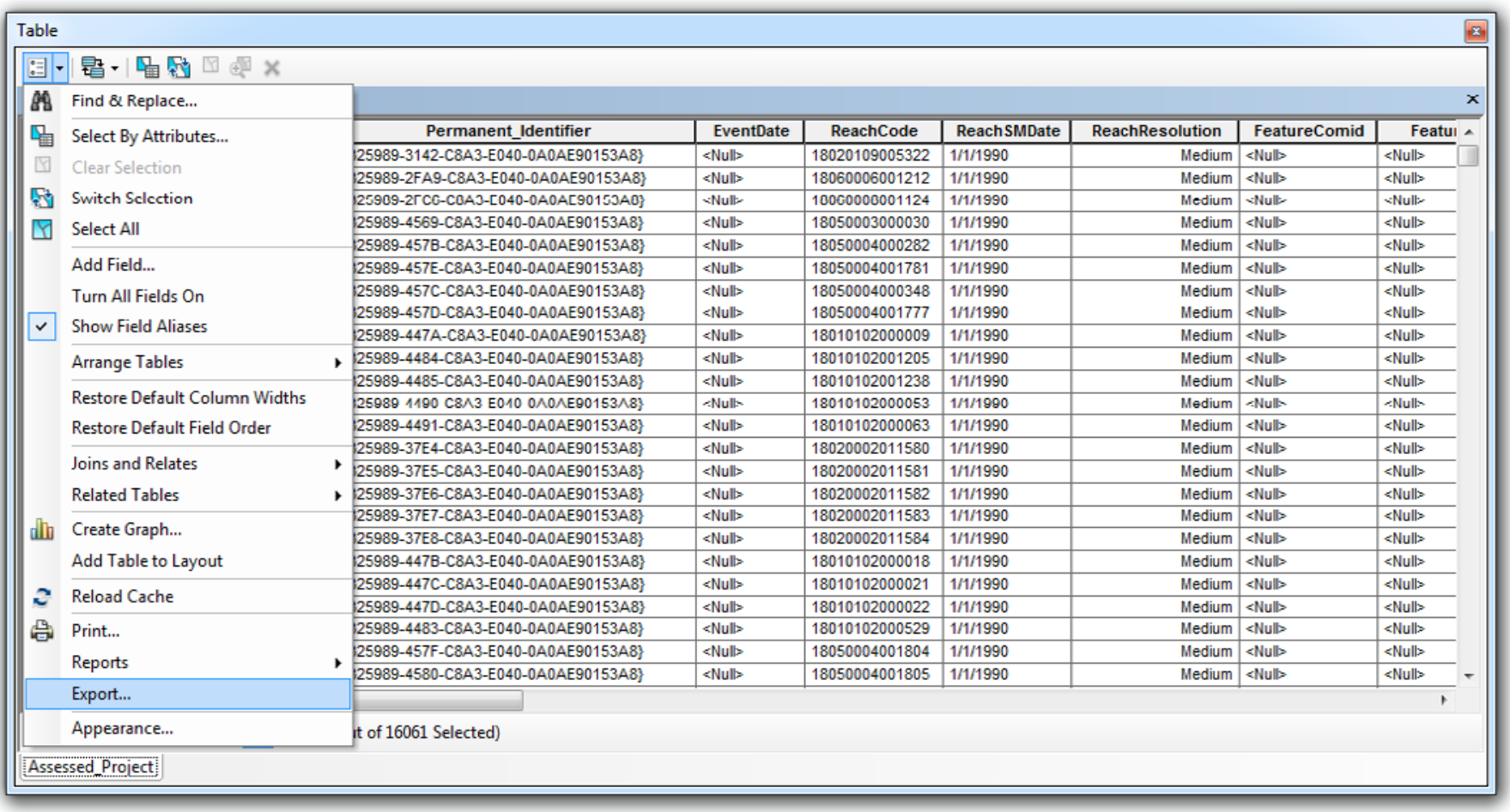

Figure 22. Screen capture of Exporting the attribute table for the prepared files; NHDflowlines, Clean Water Act Section 303(d) listed impaired waters, and total maximum daily load data layer.

Figure 23. Screen capture of saving the data table exported from ArcGIS as a .dbf file.

\section{Export Data}

\section{Export: All records}

Use the same coordinate system as:

this layer's source data

the data frame

the feature dataset you export the data into

(only applies if you export to a feature dataset in a geodatabase)

Output table:

C:WWRS_WQ\WaterQuality.gdb \mpaired.dbf

OK

Cancel 
prepared for import into the WQIS database. In ArcGIS, add the impaired waters parameter attribute table by navigating to the rad_303d geodatabase, then add the rad_303d_prgattr table (fig. 24). Next add the TMDL parameter attribute table by navigating to rad_impwtmdls geodatabase, then add the rad_impwtmdls_prgattr table.

Save these two tables as .dbf files by choosing Export under the Table Options tab. Name the tables impatt.dbf and tmdlatt.dbf, respectively. This naming convention must be followed for the WQIS database to function properly.

\section{Refreshing the WOIS Database}

Create a backup copy of the WQIS database before making any changes. This step is critical especially if any problems are encountered refreshing the WQIS database. Open the WQIS database in Microsoft Access and open the All Access Objects table of contents. Import each of the five newly created tables (Impaired.dbf, impatt.dbf, NHD.dbf, TMDL. $d b f$, and tmdlatt.dbf) by clicking on the External Data Tab, click More, then click dBASE File, then selecting the table to import. A message box should be displayed stating that "all new objects were imported successfully." The new table will be given the table name, with a 1 added (for example,
Impaired1). After importing all the new tables, compare both the new and old versions of each table (for example, Impaired and Impaired1) by opening both tables in Design View and positioning them side by side (fig. 25).

Overwrite the old version of the table with the new version by renaming the tables. Rename the new version of the table and remove the 1 from the name of each of the new tables (for example, rename Impaired1 to Impaired, overwriting the old version). A warning message will popup stating, "The name you entered already exists for another object of the same type in this database. Do you want to replace the existing table?" Click yes. Another warning message will popup stating, "You can't delete the table until its relationships to other tables have been deleted. Do you want Microsoft Access to delete the relationships now?" Click yes.

The Dates table contains the publication dates of the FWS cadastral dataset and the EPA water-quality dataset (fig. 26). The dates in this table need to be manually updated so that the dates displayed in the reports accessed using the WQIS database will be correct. Open the Dates table and input the dates previously recorded for each dataset.

Delete the RankImp and RankTMDL tables. The WQIS database cannot be properly optimized if these two tables are present. These tables will be recreated by the database when they are needed.

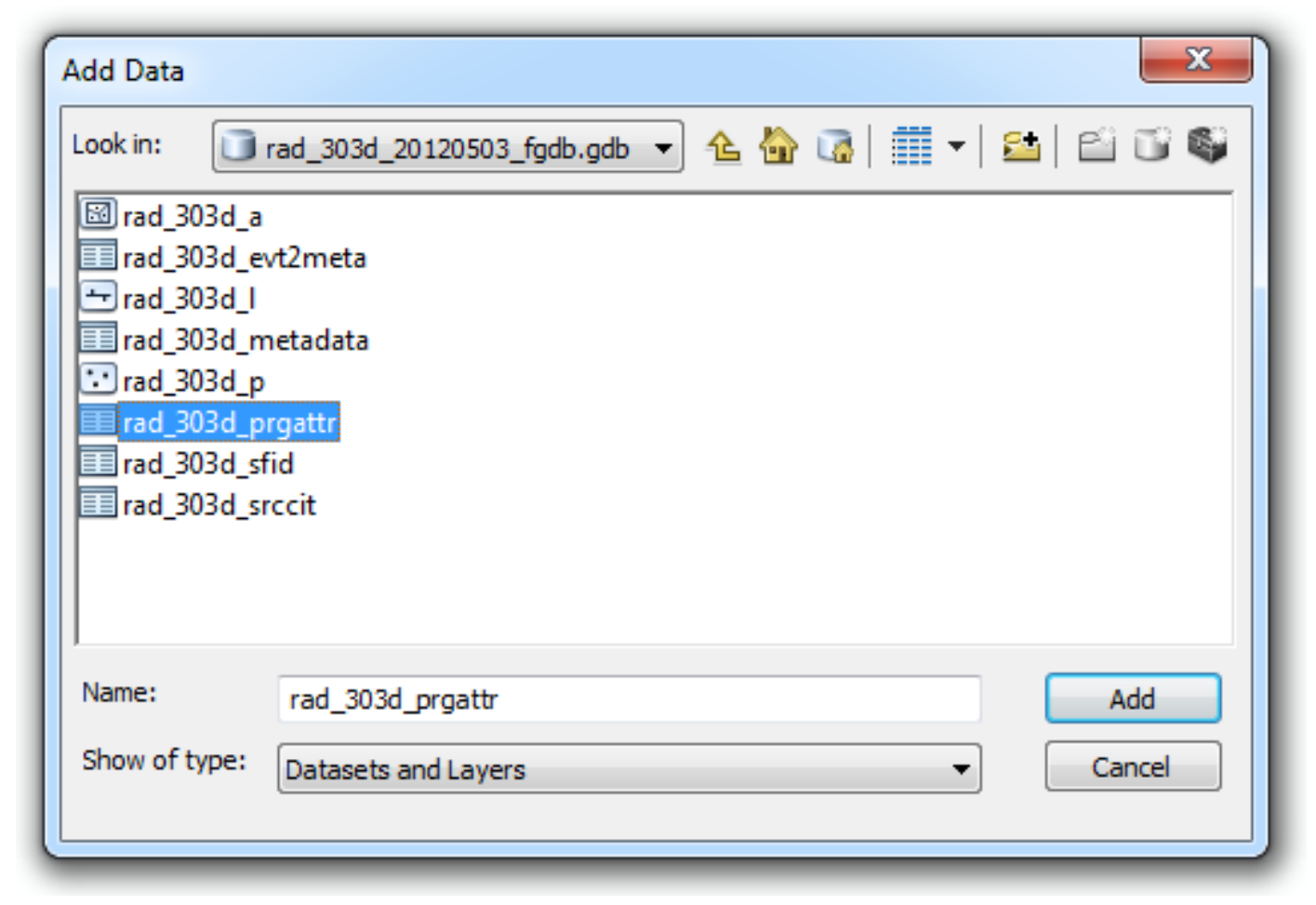

Figure 24. Screen capture of the parameter attribute table for Clean Water Act Section 303(d) impaired waters within the U.S. Environmental Protection Agency RAD_303(d) geodatabase. 


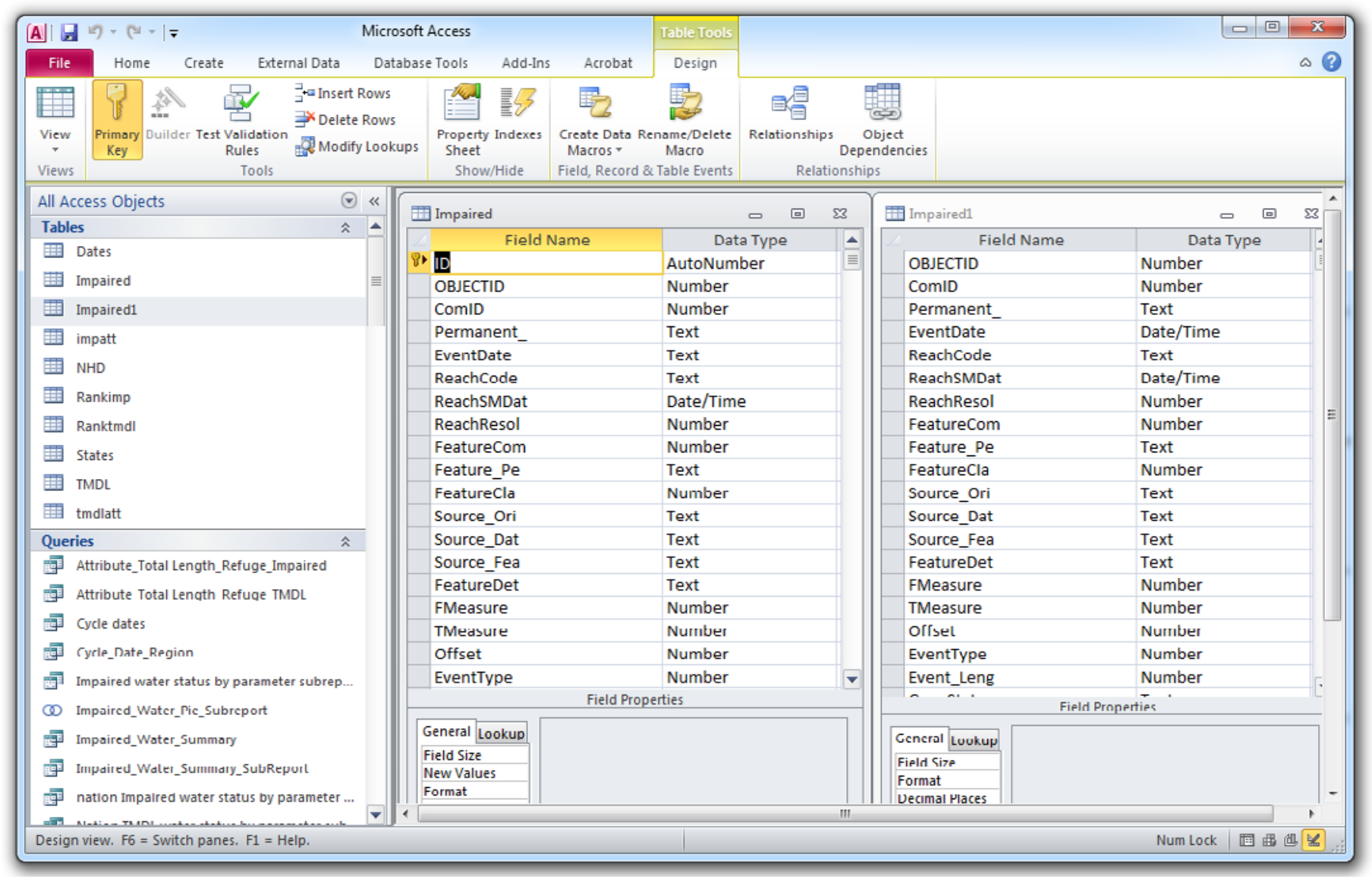

Figure 25. Screen capture showing the side-by-side comparison of fields contained in the old Impaired and new Impaired1 versions of the table.

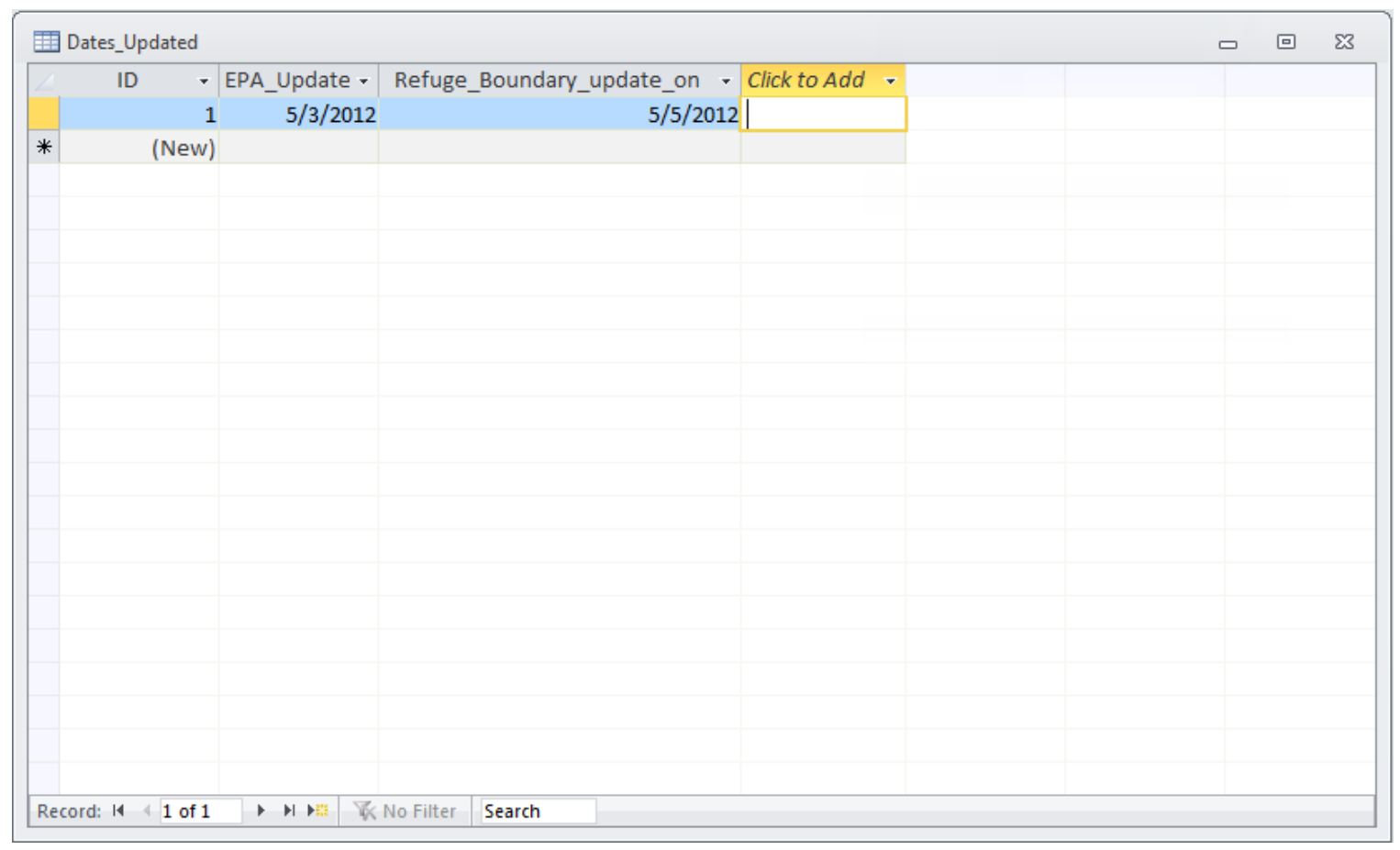

Figure 26. Screen capture showing the Dates table within the WOIS database. 


\section{Optimize the Database}

To optimize the performance of the WQIS database, click the Database Tools tab, then Analyze Performance button. Click the Queries tab in the Performance Analyzer, then click the Select All button, and click OK (fig. 27).

The Performance Analyzer returns a list of results, click select all, and then click Optimize (fig. 28). The database cannot be further optimized if the Optimize button is greyed out, click Close instead. The WQIS is now available to query.

\section{Troubleshooting}

The WQIS database was developed using a 32-bit Windows 7 operating system and Microsoft Access 2010. The WQIS may run on other Access versions and operating systems, but was not designed to do so. Upgrades of Windows and Microsoft Access in the future may require additional manipulations to ensure database functions properly. If you are running Microsoft Access 2010 on Windows 7 operating system and experience errors (for example, "An error occurred while loading... .", "Invalid procedure call or argument", or "The database cannot be opened because the VBA project contained in it cannot be read... ."), upon opening the WQIS database, first ensure that all Windows Updates have been installed and the system has been rebooted.

If all Windows Updates have been installed and the system has been rebooted and the database does not open properly, adjust the Trust Center settings. Open Microsoft Access, not the WQIS database, under the File tab, click Options (fig. 29).

Click on Trust Center in the table of contents in the Access Options box. Then click on the Trust Center Settings button (fig. 30).

Click on Macro Settings in the table of contents in the Trust Center box, ensure that the Enable all macros is enabled (fig. 31).

Click on DEP Settings in the table of contents in the Trust Center box. Uncheck the Enable Data Execution Prevention mode option (fig. 32).

Close Microsoft Access and reopen the WQIS database after making these changes.

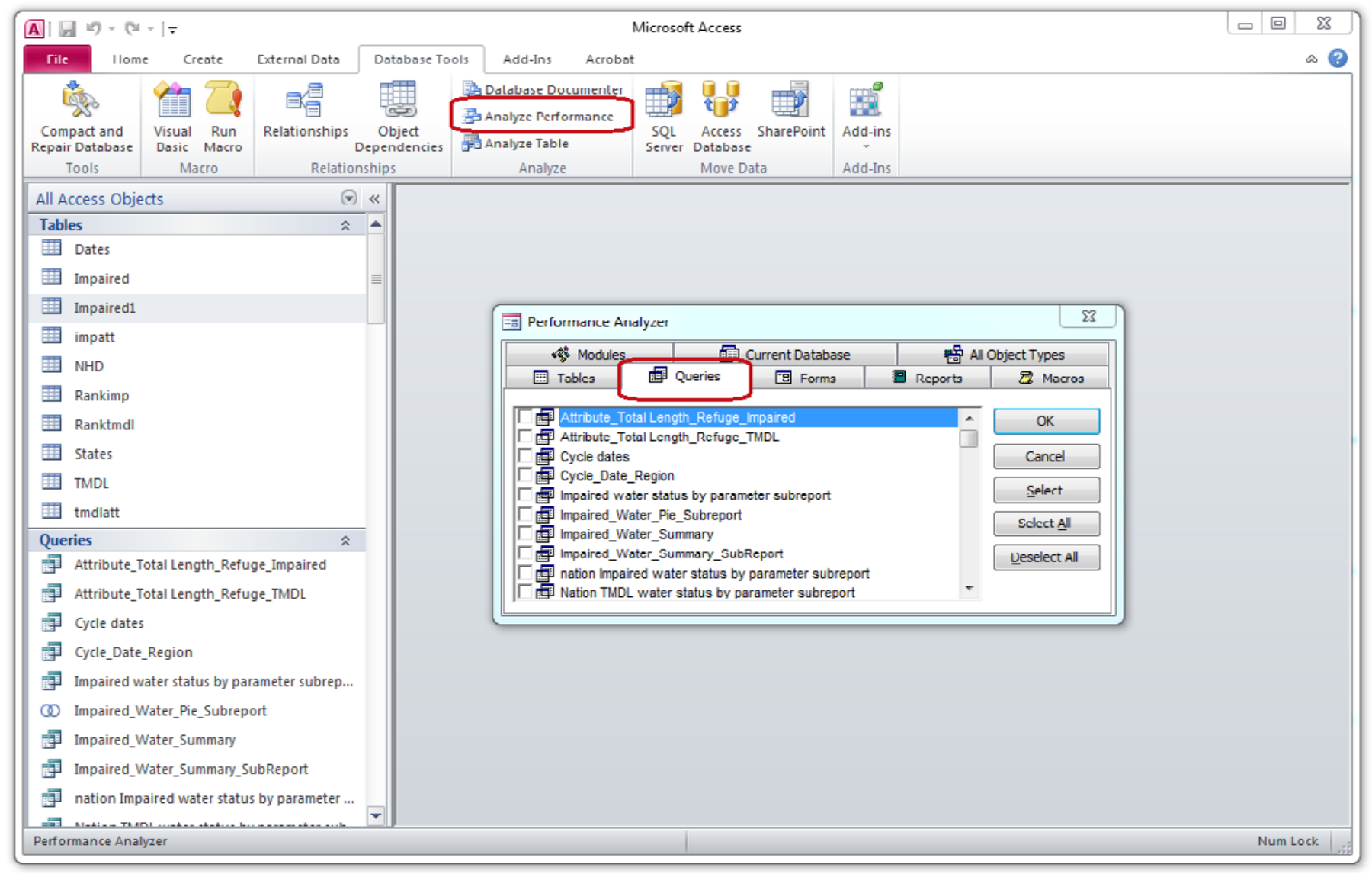

Figure 27. Screen capture of the Performance Analyzer tools in Microsoft Access. The Analyze Performance button (top) and Queries tab (bottom) are circled in red. 
Performance Analyzer

Analysis Results:

P: Table 'NHD': Change data type of field 'REACHCODE' from 'Text' to 'Double'

Table 'NHD': Change data type of field 'FWSREGION' from 'Text' to 'Long Integer'

Table 'Rankimp': Relate to table 'Rankimp'

8: Table 'Rankimp': Change data type of field 'FWSREGION' from Text' to 'Long Integer'

? Table 'Ranktmdr': Relate to table 'Ranktmdl'

OP: Table 'Ranktmdl': Change data type of field 'FWSREGION' from 'Text' to 'Long Integer'

Key:

$$
\text { I Recommendation ? Suggestion \& Idea } \checkmark \text { Fixed }
$$

-Analysis Notes:

This optimization will benefit the Query 'Attribute_Total Length_Refuge_Impaired' and potentially other objects in your database.

Using appropriate data types can improve performance when you query and access data. To assign appropriate data types, open the table in Design view and change the data type of the field to the data type the wizard suggests above. Caution: Changing a data type will erase existing data that doesn't match the new data type and will limit the kind of information you can store in the field.

\section{Optimize}

Select All

\section{Deselect A}

Close

Figure 28. Screen capture of the Performance Analyzer results. The Optimize button is circled in red.

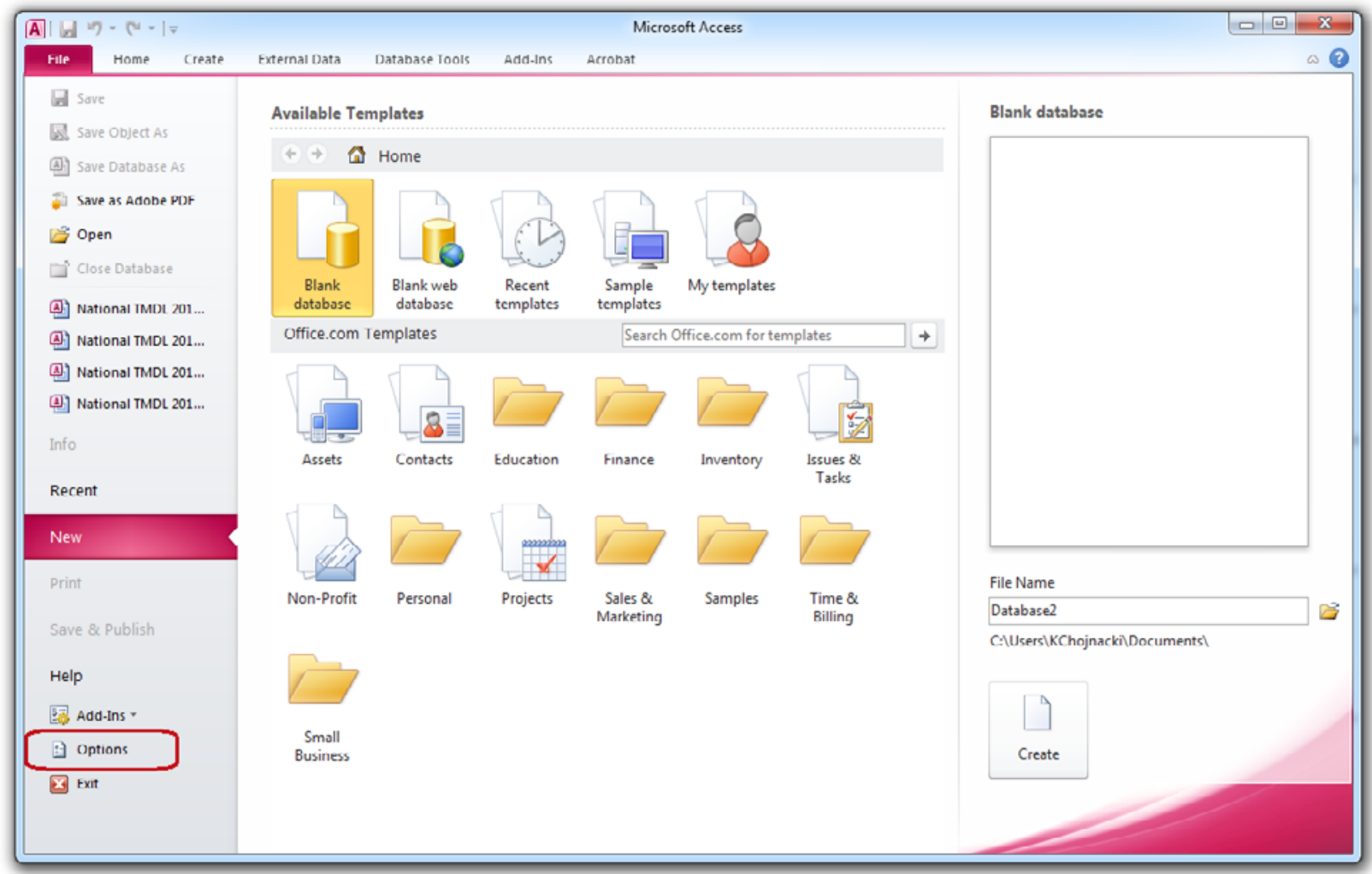

Figure 29. Screen capture of the Access Options to configure Microsoft Access to successfully run the WOIS database. The Options button is circled in red. 


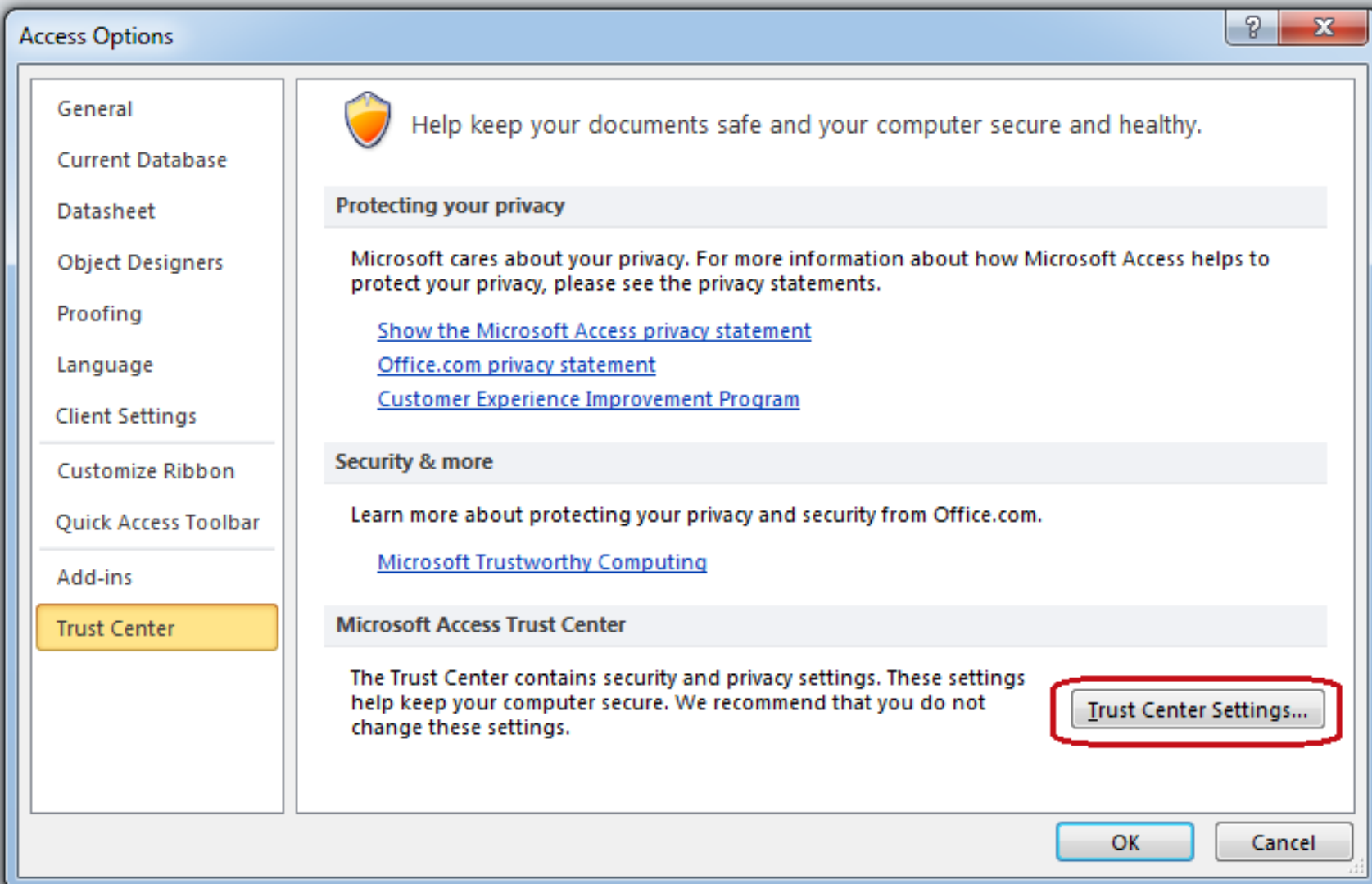

Figure 30. Screen capture of the Access Options box in Microsoft Access. The Trust Center Settings button is circled in red.

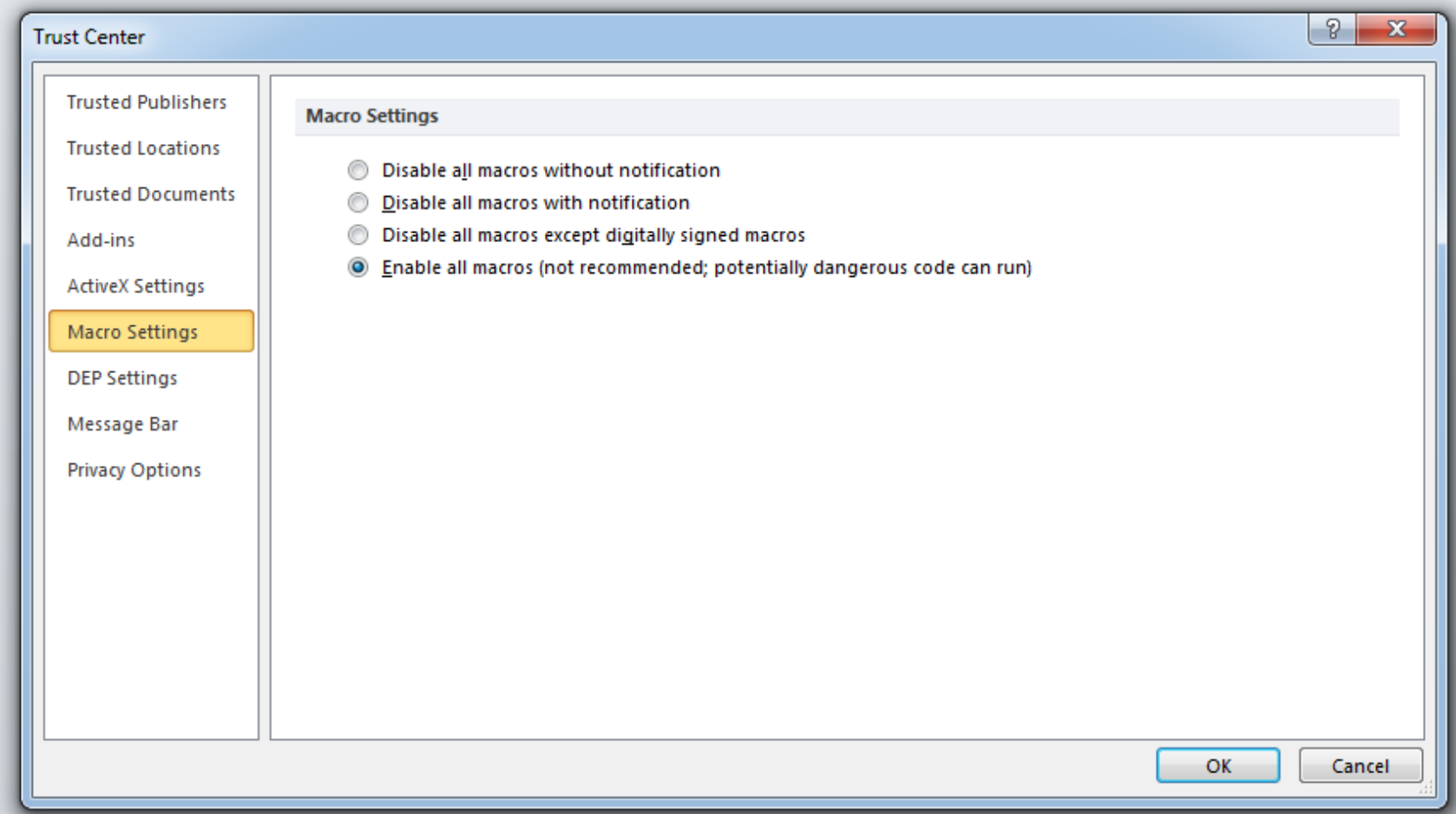

Figure 31. Screen capture of the Macro Settings within the Microsoft Access Trust Center. 


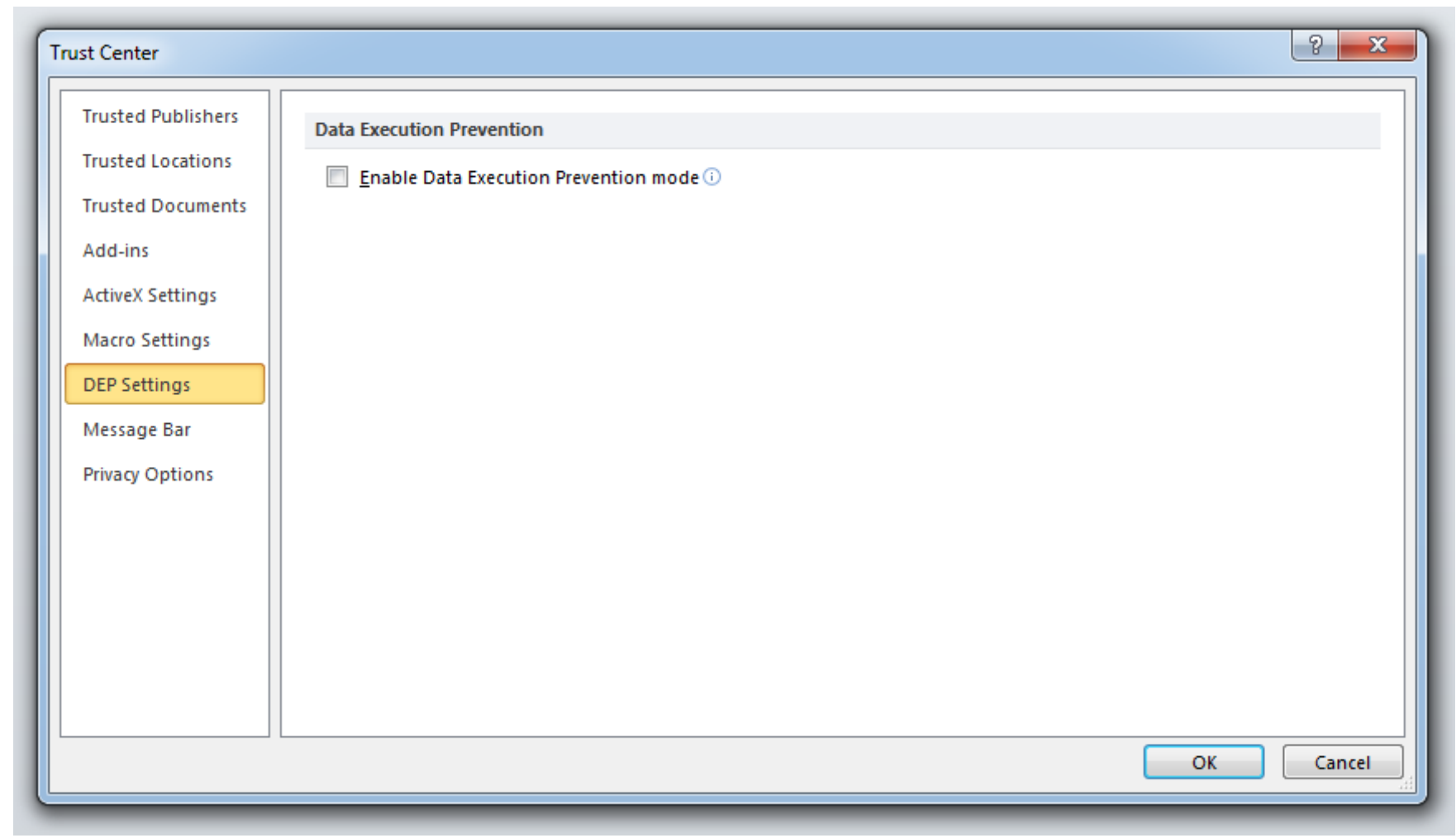

Figure 32. Screen capture of the Enable Data Execution Prevention setting in the Microsoft Access Trust Center.

\section{References Cited}

Code of Federal Regulations, 2012a, Title 50-Wildlife and fisheries, PART 16, Injurious wildlife: accessed on November 1, 2012, at http://www.gpo.gov/fdsys/browsel collectionCfraction? collection Code $=C F R \&$ searchPath $=$ Tit le $+50 \% 2$ FChapter $+I \&$ oldPath $=$ Title $+50 \&$ is Collapsed $=$ tru e\&selectedYearFrom $=2012 \&$ ycord $=1475$.

Code of Federal Regulations, 2012b, Title 40-Protection of environment, PART 130, water quality planning and management 130.7, Total maximum daily loads (TMDL) and individual water quality-based effluent limitations: accessed on September 1, 2012, at http://edocket.access.gpo.gov/ cfr_2005/julqtr/pdf/40cfr130.7.pdf.

Code of Federal Regulations, 2008, Title 40-Protection of environment, PART 112, Oil Pollution Prevention; Spill Prevention, Control, and Countermeasure Rule; Revisions to the Regulatory Definition of "Navigable Waters": accessed on September 1, 2012, at http://www.epa.gov/EPAWATER/2008/November/Day-26/w28123.htm.
Hinck, J.E., K. Chojnacki, S. Finger, G. Linder, and K. Kilbride, 2011, A geospatial approach to identify water quality issues for National Wildlife Refuges in Oregon and Washington: Journal of Fish and Wildlife Management, v. 2, issue 1, p. 12-21.

Horizon Systems Corporation, 2012, National Hydrography Dataset (NHD) Plus: U.S. Environmental Protection Agency and U.S. Geological Survey database, accessed on September 1, 2012 at http://www.horizon-systems.com/NHDPlus/.

NHDPlus Team, 2010, NHDPlus Version 1 (NHDPlusV1) User Guide: U.S. Environmental Protection Agency and U.S. Geological Survey, accessed on September 1, 2012, at http://www.horizon-systems.com/NHDPlus/NHDPlusV1_ documentation.php.

U.S. Environmental Protection Agency, 2003, Guidance for 2004 assessment, listing, and reporting requirements pursuant to Sections 303(d) and 305(b) of the Clean Water Act: accessed on September 1, 2012, at http://www.epa.gov/ owow/tmdl/tmdl0103/2004rpt_guidance.pdf. 
U.S. Environmental Protection Agency, 2012, Reach Address Database (RAD): U.S. Environmental Protection Agency database, accessed on September 1, 2012, at http://

epamap32.epa.gov/radims/.

U.S. Fish and Wildlife Service, 2011, Conserving the Future, Wildlife Refuges and the Next Generation: accessed on September 1, 2012, at http://www.fws.gov/refuges/index. html.

U.S. Fish and Wildlife Service, 2012a, Service Manual Chapters: U.S. Fish and Wildlife Service, accessed on November 1, 2012, at http://www.fws.gov/policy/manuals/.

U.S. Fish and Wildlife Service, 2012b, U.S. Fish and Wildlife Service National Cadastral Geodatabase: U.S. Fish and Wildlife Service database, accessed on September 1, 2012, at $h t t p: / / w w w . f w s . g o v / G I S / d a t a / C a d a s t r a l D B / i n d e x . h t m$.

Publishing support provided by:

Rolla Publishing Service Center

For more information concerning this publication, contact:

Director, USGS Columbia Environmental Research Center

4200 New Haven Road

Columbia, M0 65201

(573) 875-5399

Or visit the Columbia Environmental Research Center Web site at: http://www.cerc.usgs.gov/ 



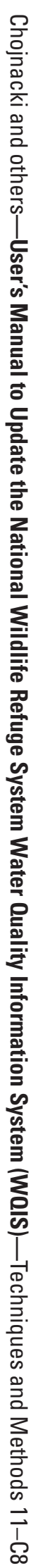

